Knight CA, Baskaran M, Bunting MJ, et al. Linking modern pollen accumulation rates to biomass: Quantitative vegetation reconstruction in the western Klamath Mountains, NW California, USA. Accepted fro publication in The Holocene. Copyright (c) 2021 SAGE Publications. https://doi.org/10.1177/0959683620988038

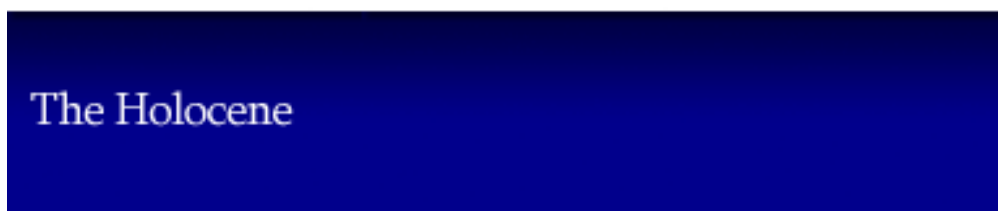

\title{
Linking modern pollen accumulation rates to biomass: Quantitative vegetation reconstruction in the western Klamath Mountains
}

\begin{tabular}{|c|c|}
\hline Journal: & The Holocene \\
\hline Manuscript ID & HOL-20-0153.R1 \\
\hline Manuscript Type: & Paper \\
\hline $\begin{array}{l}\text { Date Submitted by the } \\
\text { Author: }\end{array}$ & $\mathrm{n} / \mathrm{a}$ \\
\hline Complete List of Authors: & $\begin{array}{l}\text { Knight, Clarke; UC Berkeley, ESPM } \\
\text { Baskaran, Mark; Wayne State University } \\
\text { Bunting, M.; University of Hull, Geography } \\
\text { Champagne, Marie; USGS } \\
\text { Potts, Matthew; UC Berkeley, ESPM } \\
\text { Wahl, David; USGS, } \\
\text { Wanket, James; California State University Sacramento, Geography } \\
\text { Battles, John; UC Berkeley, ESPM }\end{array}$ \\
\hline Keywords: & $\begin{array}{l}\text { Pollen accumulation rate (PAR), quantitative reconstruction, biomass, } \\
\text { source area of pollen, Klamath Mountains, California, pollen }\end{array}$ \\
\hline Abstract: & $\begin{array}{l}\text { Quantitative reconstructions of vegetation abundance from sediment- } \\
\text { derived pollen systems provide insights into past ecological conditions. } \\
\text { Recently, the use of pollen accumulation rates (PAR, grains cm-2 yr-1) } \\
\text { has shown promise as a bioproxy for plant abundance. However, } \\
\text { successfully reconstructing region-specific vegetation dynamics using } \\
\text { PAR requires that accurate assessments of pollen deposition processes } \\
\text { be quantitatively linked to spatially-explicit measures of plant } \\
\text { abundance. Our study addressed these methodological challenges. } \\
\text { Modern PAR and vegetation data were obtained from seven lakes in the } \\
\text { western Klamath Mountains, California. To determine how to best } \\
\text { calibrate our PAR-biomass model, we first calculated the spatial area of } \\
\text { vegetation where vegetation composition and patterning is recorded by } \\
\text { changes in the pollen signal using two metrics. These metrics were an } \\
\text { assemblage-level relevant source area of pollen (aRSAP) derived from } \\
\text { extended R-value analysis and a taxon-specific relevant source area of } \\
\text { pollen (tRSAP) derived from PAR regression. To the best of our } \\
\text { knowledge, aRSAP and tRSAP have not been directly compared. We } \\
\text { found that the tRSAP estimated a smaller area for some taxa (e.g., a } \\
\text { circular area with a } 225 \text { m radius for Pinus) than the aRSAP (a circular } \\
\text { area with a } 625 \text { m radius). We fit linear models to relate PAR values } \\
\text { from modern lake sediments with empirical, distance-weighted estimates } \\
\text { of aboveground live biomass (AGLdw) for both the aRSAP and tRSAP } \\
\text { distances. In both cases, we found that the PARs of major tree taxa - } \\
\text { Pseudotsuga, Pinus, Notholithocarpus, and TCT - were statistically } \\
\text { significant and reasonably precise estimators of contemporary AGLdw. } \\
\text { However, predictions weighted by the distance defined by aRSAP tended }\end{array}$ \\
\hline
\end{tabular}


to be more precise. The relative root-mean squared error for the aRSAP biomass estimates was $9 \%$ compared to $12 \%$ for tRSAP. Our results demonstrate that calibrated PAR-biomass relationships provide a robust method to infer changes in past plant biomass.

\section{SCHOLARONE ${ }^{\text {M }}$ Manuscripts}


1 Title: Linking modern pollen accumulation rates to biomass: Quantitative vegetation

2 reconstruction in the western Klamath Mountains

3

4 Authors: Clarke A. Knight ${ }^{1}$, Mark Baskaran², M. Jane Bunting ${ }^{3}$, Marie Champagne ${ }^{4}$, Matthew D.

5 Potts $^{1}$, David Wahl ${ }^{4,5}$, James Wanket ${ }^{6}$, John J. Battles ${ }^{1}$

$6{ }^{1}$ Department of Environmental Science, Policy, and Management, University of California,

7 Berkeley, Berkeley, California 94720 USA

$8 \quad{ }^{2}$ Department of Geology, Wayne State University, Detroit, Michigan 48202 USA

$9{ }^{3}$ Department of Geography, Geology and Environment, University of Hull, Cottingham Road, 10 Hull, HU6 7RX UK

$11{ }^{4}$ US Geological Survey, Menlo Park, California 94025 USA

$12{ }^{5}$ Department of Geography, University of California, Berkeley, Berkeley, California 94720 USA

$13{ }^{6}$ Department of Geography, California State University, Sacramento, Sacramento, California 1495819 USA

15

16 Corresponding author: CAK, clarke.knight@berkeley.edu 
17 Abstract

18 Quantitative reconstructions of vegetation abundance from sediment-derived pollen systems

19 provide unique insights into past ecological conditions. Recently, the use of pollen accumulation

20 rates (PAR, grains $\mathrm{cm}^{-2} \mathrm{yr}^{-1}$ ) has shown promise as a bioproxy for plant abundance. However,

21 successfully reconstructing region-specific vegetation dynamics using PAR requires that

22 accurate assessments of pollen deposition processes be deterministically quantitatively linked to

23 spatially-explicit measures of plant abundance. Our study addressed these methodological

24 challenges. Modern PAR and vegetation data were obtained from seven lakes in the western

25 Klamath Mountains, California. To determine how to best calibrate our PAR-biomass model, we

26 first calculated the spatial area of vegetation where vegetation composition and patterning is

27 recorded by changes in the pollen signal using two metrics. These metrics were an assemblage-

28 level relevant source area of pollen (aRSAP) derived from extended R-value analysis (sensu

29 Sugita 1993) and a taxon-specific relevant source area of pollen (tRSAP) derived from PAR

30 regression (sensu Jackson 1990). To the best of our knowledge, aRSAP and tRSAP have not

31 been directly compared. We found that the tRSAP estimated a smaller area for some taxa (e.g., a

32 circular area with a $225 \mathrm{~m}$ radius for Pinus) than the aRSAP (a circular area with a $625 \mathrm{~m}$

33 radius). We fit linear models to relate PAR values from modern lake sediments with empirical,

34 distance-weighted estimates of aboveground live biomass $\left(\mathrm{AGL}_{\mathrm{dw}}\right)$ for both the aRSAP and

35 tRSAP distances. In both cases, we found that the PARs of major tree taxa-Pseudotsuga, Pinus,

36 Notholithocarpus, and TCT (Taxodiaceae, Cupressaceae, and Taxaceae families) - were

37 statistically significant and reliable-reasonably precise estimators of contemporary $\mathrm{AGL}_{\mathrm{dw}}$.

38 However, predictions weighted by the distance defined by aRSAP tended to be more precise.

39 The relative root-mean squared error for the aRSAP biomass estimates was $9 \%$ compared to $12 \%$ 
40 for tRSAP. Our results demonstrate that calibrated PAR-biomass relationships provide a robust

41 method to infer changes in past plant biomass.

42

43 Key words:

44 Pollen accumulation rate (PAR), quantitative reconstruction, biomass, source area of pollen,

45 Klamath Mountains, California 


\section{1. Introduction}

47 Quantitative reconstruction of past plant abundance has been an important goal in paleoecology 48 since the field's inception (Von Post 1918) and a major research frontier spanning decades 49 (Davis and Deevey 1964, Likens and Davis 1975, Davis et al. 1984, Hicks 2001, Seppä et al. 50 2009, Matthias and Giesecke 2014, Marquer et al. 2014). Currently, t $\underline{T}$ he research community 51 lacks a complete understanding of how the pollen signal reflects plant population parameters 52 (e.g., biomass), and therefore past population change (Fagerlind 1952, Davis et al. 1984, Prentice 53 1988, Seppä et al. 2009). Developing methods to quantitatively reconstruct past plant 54 populations would aid climate science and restoration ecology. In climate science, for example, 55 quantitative reconstructions of past plant populations would allow better understanding of long56 term ecosystem dynamics (Galliard et al. 2000) and provide past analogues to test complex 57 climate models that account for the effects of landcover on the climate system (Galliard et al. 58 2010). Restoration ecology would benefit from an improved understanding of the impact of 59 disturbances (natural and anthropogenic) on landscapes and ecosystems (Broström et al. 1998, 60 Crawford et al. 2015) and from the increased participation by paleo-ecologists in the debates of 61 modern restoration ecology (Swetnam et al. 1999, Hellman et al. 2009).

Palynologists often use pollen percentage data in pollen-vegetation models to reconstruct 63 landcover and understand past plant populations, but this approach does not provide separate 64 reconstructions for each taxon's plant population change (Davis 1963, Prentice 1988). Relative 65 changes in abundance of species have been inferred form Bayesian hierarchical spatio-temporal 66 pollen-vegetation models (Dawson et al. 2019). In contrast, pollen accumulation rates (PAR) - a
67 measure of the rate of pollen deposition at the sediment surface per unit area during a given time 68 period (e.g., grains $\mathrm{cm}^{-2} \mathrm{yr}^{-1}$, Davis and Deevey 1964) - depend solely on the abundance of the 
69 plant taxa producing that pollen type around the collection site. That is, the PAR for each taxon

70 is independent of all other taxa. PAR allows results from different regions to be directly

71 compared, irrespective of other taxa in the investigations (Hicks and Hyvärinen 1999, Giesecke

72 and Fontana 2008). PAR has been used to reconstruct not only landcover, but also population

73 dynamics and plant biomass (Seppä et al. 2009, Theuerkauf et al. 2012, Matthias and Giesecke

74 2014). For example, PAR has been used to reconstruct past population growth rates (Bennett

75 1983, 1986, MacDonald 1993, Giesecke 2005) and to reconstruct Holocene biomass records in at

76 least two areas: the Finnish boreal zone (Seppä et al. 2009) and a sub-alpine forest in Utah

77 (Morris et al. 2015).

PAR is not a simple reflection of vegetation abundance because the pollen signal is a

79 distance-weighted measure of taxa abundance in the surrounding vegetation, responding to the

80 structure of the plant community as well as species abundance (Jackson 1990). Modern PAR

81 values must be quantitatively correlated with modern plant population data from the lake

82 surroundings in order to parameterize the PAR-population relationship before fossil PAR records

83 can be interpreted in terms of past plant population change. This correlation step requires

84 accurate vegetation data from forest inventories (Seppä et al. 2009, Matthias and Giesecke 2014),

85 careful field surveys (Bunting et al. 2013), or well-resolved spatial imagery coupled with

86 ground-truthing (Han et al. 2017) that encompasses the relevant source area of pollen ('RSAP',

87 discussed below and in section 2.3, sensu Sugita 1993). Previous work has shown a linear

88 relationship between PAR and distance-weighted biomass across a range of lake sites in

89 northeastern Germany (Matthias and Giesecke 2014).

90 In addition to quantitative vegetation data, reliable PAR data require a robust chronology

91 of the pollen system being studied. Ideally, a sedimentary core for PAR data collection has two 
92 features: it is obtained from an undisturbed lake environment where sediment accumulates

93 evenly over time, and the resulting sediment is dated at high resolution. Where lakes are found to

94 have stable sedimentary conditions, reliable PAR datasets can be obtained (e.g., Ritchie 1969,

95 Hyvärinen 1975, Seppä and Hicks 2006) though there may still be channel funneling. The recent

96 development of Bayesian tools has improved the construction of chronologies from isotopic data

97 such as ${ }^{210} \mathrm{~Pb}$ activity measurements, giving more reliable measures of uncertainty (Aquino-

98 López et al. 2018).

99 Lastly, all sedimentary basins have a relevant source area of pollen (RSAP), which is

100 sometimes referred to as the "pollenshed" of the basin (sensu Sugita 1993). The basic premise is

101 that vegetation within a certain area distance of the basin corresponds to the quantity and type of 102 pollen deposited at the site. With distance from the lake shore, Ccorrelations between plant

103 abundance and pollen loading are expected to improve-close to the lake shore, then approach an 104 asymptote at some distance because source vegetation of pollen far from the basin should have 105 much less influence on the pollen representation than vegetation closer to the basin. Estimating 106 the RSAP is a key step for quantitative calibration because it provides information about the 107 spatial extent of any subsequent vegetation reconstruction (Sugita et al. 1999, Bunting et al. 108 2004, Hellman et al. 2009). To our knowledge, the distinction between an assemblage-level 109 pollenshed RSAP (aRRSAP, Sugita 1993) and taxa-specific RSAPpollensheds (tRRRAP, sensu 110 Jackson 1990, Matthias and Giesecke 2014) has not yet been drawn within the same basin (Table $111 \underline{X}$ ). Comparing these estimates provides insight about how pollen assemblages "sense" 112 vegetation, which is critical to the extraction of vegetation information from pollen data.

113 Given the methodological challenges, the application of calibrated PAR-biomass transfer 114 functions to any ecosystem is not routine. This paper develops PAR-biomass models using short 
15 cores from seven small lakes in the western Klamath Mountains, California, and follows the

116 general approach used in previous studies (e.g., Seppä et al. 2009, Matthias and Giesecke 2014)

117 whilst critically evaluating each step in the process. The Klamath bioregion contains numerous

118 small lakes and is an area where Holocene-length paleoecological records have already provided

119 a portrait of ecological change (Fig. 1). We measured modern PAR from lake sediments and

120 acquired vegetation abundance data to achieve three goals: 1) to understand the spatial

121 relationship between pollen assemblages flux in small lakes and surrounding vegetation cover,

122 through modeling of the aRSAP and tRSAP, 2) to calibrate a PAR-biomass model using

123 distance-weighted biomass for major tree taxa, and 3) to assess the potential of this model to

124 reconstruct past changes in assemblage-wide biomass from the region.

\section{2. Background}

127 Below, we describe the study area's physical features (2.1), our pollen-vegetation modelling 128 approach (2.2), and the methodology used to estimate aRSAP and tRSAP (2.3).

131 The Klamath bioregion, a physically and floristically diverse area in northwestern California 132 (Whittaker 1960, Cheng 2004), contains hundreds of small lakes. Many lakes are found at high

133 elevations and are glacial in origin, but there are also landslide-created lakes at low- and mid134 elevations in the western portion of the region (Wahrhaftig and Birman 1965). The landscape has 135 deep catchments and steep mountains (Irwin 1981)), and the climate is Mediterranean, consisting 136 of cool, wet winters and warm, dry summers (Skinner et al. 2006). Prior to $20^{\text {th }}$ century fire 
137 suppression, the landscape had a mixed-severity fire regime characterized by mostly small, low138 intensity, frequent fires, and infrequent large burns of mixed-severity (Taylor and Skinner 2003).

Our study focused on the western Klamath Mountains where low-elevation forests $140 \quad(<600-800 \mathrm{~m})$ are dominated by Pseudotsuga menziesii (Douglas-fir). Multiple Pinus (pine) 141 species including Pinus lambertiana (sugar pine), Pinus jeffreyi (Jeffrey pine), and Pinus 142 ponderosa (ponderosa pine) are also common but less frequent than Douglas-fir. The most 143 common broadleaf tree species in the low-elevation forests are Notholithocarpus densiflorus 144 (tanoak), followed by Arbutus menziesii (Pacific madrone), Chrysolepis chrysophylla (golden 145 chinquapin), and Quercus kelloggii (California black oak). Chamaecyparis lawsoniana (Port146 Orford-cedar) is mainly found in riparian areas but can be found on slopes. Higher-elevation 147 montane forests are dominated by Abies concolor (white fir) and Abies magnifica (red fir; 148 Sawyer and Thornburg, 1977), whereas sub-alpine (above $\sim 1700 \mathrm{~m}$ ) zones include Tsuga 149 mertensiana (mountain hemlock) and Picea breweriana (Brewer spruce) (Sawyer and Thornburg 150 1977). On areas of ultramafic soils derived from serpentinite and peridotite bedrock, Jeffrey pine, 151 Pinus monticola (western white pine) and Calocedrus decurrens (incense-cedar) are the 152 dominant forest taxa (Whittaker 1960; nomenclature follows Hickman 1993). 154 minimal stream inputs, and shallow slopes (Table 1, Fig. 1). Vegetation around the lakes is 155 representative of the diverse mixed conifer forest of the Klamath bioregion (Hudiburg et al. 156 2009) although the dominant overstory varies at each lake site. Holocene-length pollen records 157 (percentage and PAR) already exist for three of the seven lakes and suggest that the modern 158 forest structure and composition have been relatively stable for the last 2,000 years (Wanket 
59 2002) but also imply a 3,000-year historic high of Douglas-fir in the contemporary forest

160 (Crawford et al. 2015).

\subsection{Pollen-vegetation models}

162 Linear pollen-vegetation models (PVMs) have a long history of use in palynology (Davis 1963, 163 2000; Andersen 1970; Prentice 1985, 1988; Sugita 1993, 1994; Bunting and Middleton 2005,

164 Bunting et al. 2013). PVMs use the relationship between pollen assemblages and vegetation to 165 infer past vegetation composition or structure from fossil pollen data. The main strengths of 166 linear PVMs are: 1) they provide the means to reconstruct vegetation from landscapes with no 167 modern analogue; 2) they have been widely tested against empirical data in quantitative 168 reconstruction research (e.g., Davis 1963, Andersen 1970, Prentice 1985, Sugita 1993, Bunting 169 and Hjelle 2010); and 3) they have been successfully validated in at least one region (southern 170 Sweden, Sugita 2007a, b; Hellman et al. 2008a, b).

171 In this work, we used a version of Sutton's original PVM model (Sutton 1947, 1953)

172 inverted by Prentice (1985) and modified by Sugita (1994) for lake environments. This model's

173 form - called Prentice-Sugita-Sutton - assumes that pollen could land anywhere on the lake

174 surface and would be perfectly mixed in the water column before being deposited on the lakebed.

175 The Prentice-Sugita-Sutton model also assumes that pollen transport is largely via wind above

176 the canopy and gravity beneath the canopy, and that the sampling basin is circular with uniform

177 wind in every direction (Sugita 1994, full list of assumptions in the supplement). Under this

178 approach, we a) divide the vegetation into rings, b) distance-weight each ring, and c) compare 179 the PAR from the basin with the summed distance weighting from one or more rings, working

180 out from the edge of the basin. This model calculates the total pollen influx from each source 181 across the whole lake. Its simplest linear form is: 
183 where,

$184 Y_{i k}=$ pollen influx for a taxon $i$ at site $k$

$185 \quad \alpha_{\mathrm{i}}=$ pollen productivity of taxon $i$

$186 \psi_{i k}=$ the distance-weighted plant abundance (DWPA) of taxon $i$ around site $k$ with the 187 weighting term reflecting the pollen dispersal of taxon $i$ (weighting term calculation shown in 188 Eqequation. 3).

190 DWPA $\left(\psi_{i k}\right)$ is defined as:

192 where,

$193 R=$ the radius of the canopy opening in which the sample site is located

$194 X_{i k}(z)=$ the plant abundance measure consisting of the contribution of taxon $i$ to the pollen 195 assemblage formed at site $k$ from plants located distance $z$ from sampling location $k$, and $\mathrm{g}_{\mathrm{i}}(\mathrm{z})$ is 196 the distance weighting term for taxon $\mathrm{i}$ at distance $\mathrm{z}$ from any sampling location. 197 198 The Prentice-Sugita-Sutton weighting term $g_{i}$ for taxon $i$ at distance $z$ is calculated using: 201 and

$202 z=$ distance

$203 \gamma=$ a coefficient of 0.125 (Prentice 1985)

$204 \quad v_{g}=$ approximated by $v_{s}\left(\right.$ fall speed, $\left.\mathrm{m} \mathrm{sec}^{-1}\right)$

$$
\begin{aligned}
g_{i}(z) & =b_{i} \gamma z^{\gamma-1} e^{b_{i} z^{\gamma}} \\
\text { where } b_{i} & =\frac{4 v_{g}}{n u \sqrt{\pi C_{z}}}
\end{aligned}
$$


$205 C_{z}=$ the vertical diffusion coefficient $\left(\mathrm{m}^{1 / 8}\right)$

$$
\Psi_{i k}=\int_{R}^{\zeta} X_{i k}(z) g_{i}(z) d z+\int_{\zeta}^{\infty} X_{i k}(z) g_{i}(z) d z
$$

Which can be written as

$$
Y_{i k}=\alpha_{i} \psi_{i k}+\omega_{i}
$$

\subsection{Spatial area represented by the pollen record}

218 We estimated the spatial extent of our sites' pollenshedssource area of pollen in two ways

219 (definitions in Table 2). We calculated the standard assemblage-specific metric - the relevant 220 source area of pollen (aRSAP) - which is defined as the area beyond which the correlation 221 between pollen and vegetation does not improve (Sugita 1993). Estimates of aRSAP can be 222 extracted from extended R-value (ERV) analysis using pollen percentage data (Parsons and 223 Prentice 1981). ERV analysis is the process of solving $n$ equations for $2 n$ unknowns in order to 224 extract the parameter estimates, where ERV sub-models 1, 2 and 3 are the underlying vegetation225 pollen relationship models. The three sub-models define background pollen differently (Sugita 226 1994). Whereas models 1 and 2 use pollen data and vegetation percentages (Parsons and Prentice 227 1981), model 3 uses pollen percentages and plant abundance data in absolute units (e.g., biomass 
228 per area) (Sugita 1994). Using the maximum likelihood method, ERV models iteratively fit the 229 relationship between pollen and vegetation percentages (Bunting and Hjelle 2010). Maximum 230 likelihood function scores measure the goodness of fit between pollen percentages and distance231 weighted plant abundance. The aRSAP can be estimated from visual inspection of the likelihood 232 function score plotted against distance; it is the point at which scores approach an asymptote 233 (Sugita et al. 1999, Bunting et al. 2005).

234 We then calculated a taxon-specific metric of the relevant source area (tRSAP) to 235 compare to the aRSAP. We call the tRSAP the distance beyond which the correlation between 236 PAR and DWPA summed to that distance does not improve (Jackson 1990). We fit a linear 237 equation (equation 5) for each individual taxon because both y and $\psi$ are measured in 238 independent terms. We again used the ring source model, which converts the integral into a 239 summation. That is, we summed the value for each of the rings and $g_{i}(z)$ includes ring area in 240 this formulation. As with aRSAP, tRSAP can be estimated from visual inspection of the $\mathrm{R}^{2}$ value 241 against the distance from the lake shore (m) (Matthias and Giesecke 2014).

\section{3. Methods}

244 Fitting PAR-biomass relationships requires a number of steps shown in a flowchart (Fig. 2) with 245 numbers matching the following sections.

\section{$247 \quad 3.1$ Lake selection and core sampling}

248 We used the following criteria to determine suitable lake sites: small size (radius approximately $249100 \mathrm{~m}$ ), no permanent outflow, simple basin, and core length greater than $25 \mathrm{~cm}$. Ten such lakes 250 were identified from topographical maps and satellite imagery as promising, but each were 
251 assessed in the field. Out of this collection, seven lakes were viable and selected for ${ }^{210} \mathrm{~Pb}$ dating.

252 During the summer of 2018 , short cores $(\sim 50 \mathrm{~cm})$ of $7 \mathrm{~cm}$ diameter were taken from each lake's 253 center using either a gravity corer (Ogaromtoc, Fish Lakes) or a piston corer (all other lakes).

254 The sediment-water interface was immobilized by sodium polyacrylate for transport. Cores were 255 later split and sectioned in the laboratory.

\subsection{Sediment dating, age-depth model, and sediment lithology}

257 We used lead-210 $\left({ }^{210} \mathrm{~Pb} ; 22.3 \mathrm{yr}\right.$ half-life $)$ to assign ages to sediment deposited in the last 150

258 years. Surface bulk sediments from $0 \mathrm{~cm}$ to a maximum of $45 \mathrm{~cm}$ were taken from each core and 259 dried to $105^{\circ} \mathrm{C}$ (see Tables $\left.\mathrm{S} 1-\mathrm{S} 7\right) .{ }^{210} \mathrm{~Pb}$ activity was determined by alpha spectrometry (see SI

260 for complete dating methodology).; ${ }^{210} \mathrm{P}$. An aliquot of 0.2 to $1.0 \mathrm{~g}$ of dried and pulverized

261 sample was digested using concentrated $\mathrm{HF}, \mathrm{HNO}_{3}$, and $\mathrm{HCl}$ and a known amount of ${ }^{209} \mathrm{Po}$ spike

262 in an oven at $90^{\circ} \mathrm{C}$ for -24 hours. The digested solution was dried, and the residue was mixed

263 with $1 \mathrm{M} H \mathrm{HCl}$ until the $\mathrm{pH}$ was -2 . Auto plating of Po was cold plated onto an $\mathrm{Ag}$ disk for 24

264 hours at room temperature (Jweda and Baskaran 2011). The plated disk was assayed for Po using

265 Octete PC ORTEC alpha spectrometer. The reagent blanks were run simultaneously with each

266 batch of eight samples and were subtracted. Certified reference materials were periodically rum.

267 For the determination of parent supported (i.e., background) ${ }^{210} \mathrm{~Pb}$, several samples were run for 268 the activity of ${ }^{226} \mathrm{Ra}$ (using 352 and $609 \mathrm{keV}$ ) along with ${ }^{137} \mathrm{Cs}$ (661.6 keV) by Ge well detector

269 (Baskaran et al. 2015). Small sample sizes prevented reliable ${ }^{137} \mathrm{Cs}$ from being obtained.

270 We used the Bayesian-based Plum software to develop age models from excess (unsupported)

$271{ }^{210} \mathrm{~Pb}$ data (Aquino-López et al. 2018). The Plum model is related to the constant rate of supply

272 (CRS) method (Appleby and Oldfield 1978) and retains two of the basic assumptions of CRS:

273 the rate of supply of ${ }^{210} \mathrm{~Pb}$ is constant and there is no vertical mixing of radionuclides. Testing 
279 age-depth function (Blaauw and Christen 2011). This algorithm results in a probability envelope

280 around the mean age model. The envelope allows the precision at any depth to be estimated

281 explicitly. Plum makes use of prior information to determine the datable horizon, which is

282 affected by two factors: the precision of methodology (alpha versus gamma counting) and the

283 initial amount of excess lead. In Plum, the chronology limit is determined by the rate of supply

284 ef $^{210} \mathrm{~Pb}$ to the site and the equipment error, usually $\sim 3 \mathrm{~Bq} / \mathrm{kg}$ for a sample size of $1 \mathrm{~g}$ by alpha

285 spectrometry for research laboratories. Supported ${ }^{210} \mathrm{~Pb}$ activities were determined from the 286 direct measurements of ${ }^{226} \mathrm{Ra}$ by gamma-ray spectrometry.

\subsection{Pollen analysis}

290 the top $0.5 \mathrm{~cm}$ of each core and were processed according to standard pollen preparation

291 procedures (Faegri and Iversen 1989) but modified to include two steps: 1) sieving with 5-and

292153 -micron mesh under vacuum and 2) swirling, with the less dense fractions retained. These

293 steps draw oneurrent US Geological Survey protocol (Tom Sheehan, personal communication),

294 which is based on DDoher's palynomorph methodology and current United States Geological

295 Survey procedures (Doher 1980). One Lycopodium spore tracer tablets containing 20,848 spores

296 wereas added to each sample to calculate pollen concentration (Stockmarr 1971, Faegri and 
297 Iversen 1989). Acetolysis and sieving steps were repeated for samples containing high amounts 
20 Lycopodium marker grains, pollen concentrations $\left(C_{i}\right.$, grains $\left.\mathrm{cm}^{-3}\right)$ were calculated for each

321 pollen type $i$ using the following equation:

$322 \quad \epsilon_{i}=-\frac{A_{i}-*-t_{a}}{t_{\epsilon} *-V_{i}}$

323 Where $A_{i}$ is the number of pollen grains counted for each taxon $i, t_{\theta}$ is the number of added

324 marker grains, $L_{\epsilon}$ is the number of counted marker grains in each slide, and $V_{i}$ is the volume of

325 the pollen sample (e.g., $0.63 \mathrm{~cm}^{3}$ ) (Stockmarr 1971), and -Coneentrations were used for PAR

326 ealeulations by multiplying the concentration values by the sediment accumulation rate (Davis

327 and Deevey 1964), which differed by lake site and was determined by the Plum age model in

328 increments of $0.5 \mathrm{~cm}$ (see SI for equations used). The equation used was:

$329 P A R_{i}=-G_{i^{-}} * S$

330 Where $P A R_{i}$ is the pollen aceumulation rate for $\operatorname{tax}$ on $i, C_{i}$ is the pollen concentration (grains $\mathrm{cm}^{-}$

$331{ }^{3}$ ) for taxon $i$, and $S$ is the sedimentation rate (em $\mathrm{yr}^{-1}$ ) (Davis and Deevey 1964$)$.

3333.5 Forest inventories

334 We used cruising prisms (wedges of glass with a known size/angle) to determine the basal area 335 of the dominant pollen-producing taxa within $750 \mathrm{~m}$ from each lake's shoreline (USDA Forest 336 Service 2000). The prism method employs variable plot radius sampling at the stand level.

337 Transects in eight directions (N, S, E, W, NE, NW, SE, SW) from the lake shore were sampled.

338 The basal area of live trees was measured using the prisms were taken every $50 \mathrm{~m}$ along the 339 transects, following Han et al. 2017 (Fig. 3).

340 We used aboveground live tree biomass (AGL) as the specific measure of abundance that 341 is distance weighted. To estimate AGL from basal area measurements, we developed species342 specific allometric equations using contemporary data from the US Forest Service Forest 
Inventory and Analysis program (FIA). From the FIA plots inventoried in Six Rivers National Forest between 2001 and 2017 (FIADB 2020), we calculated plot-level basal area $\left(\mathrm{m}^{2} \mathrm{ha}^{-1}\right)$ for every species in the plot and linked it to the estimate of plot-level aboveground live biomass (Mg $346 \mathrm{ha}^{-1}$ ) for each species ( $\mathrm{n}=3,428$ plot-by-species observations). AGL was estimated using the 347 regional model of tree biomass (Zhou and Hemstrom 2009). For every species, we predicted 348 AGL as a function of basal area using a linear log-log (natural) equation (sensu Knight et al. 349 2020).

351 Specifically,

353 where $\ln \left(\mathrm{AGL}_{\mathrm{ij}}\right)$ is the natural $\log$ of aboveground live biomass for species $i$ in plot $j, \ln$ (Basal $354 \mathrm{Area}_{\mathrm{ij}}$ ) is the natural $\log$ of tree basal area for species $i$ in plot $j, \beta_{0 \mathrm{i}}$ is the intercept for species $i$, 355 and $\beta_{1 \mathrm{i}}$ is the slope coefficient for species $i$. For the six most abundant species that accounted for $35690 \%$ of the basal area, fits ranged from a low of 0.85 for sugar pine to a high of 0.97 for Port357 Orford-cedar (Table S8). With these equations and field measurements of species basal area, we 358 calculated the AGL of each species in the prism sample.

3603.6 ERV analysis and estimation of aRSAP

361 The aRSAP values were extracted from conventional ERV analysis using model 3. We used 362 PolERV from the software suite HUMPOL (Bunting and Middleton 2005) which has the same 363 core code (erv-v6.exe and polsim-v3.exe) as other ERV software, e.g. POLLSCAPE (Sugita 364 1994). In order to meet the requirement that the number of sites is at least twice the number of 365 taxa used in ERV analysis (Soepboer et al. 2007), we analyzed sub-sets of three taxa across the 
366 seven sites using the same reference taxon (TCT) every time. For example, one such sub-set

367 combination was TCT, Pseudotsuga, and Pinus. We selected TCT as the reference taxon (i.e., 368 specified that TCT has a relative pollen productivity of 1.0) for several reasons. First, a scatter 369 plot of TCT pollen values and unscaled distance weighted plant abundance is positive and linear 370 (Fig. S1). Second, TCT has an estimated relative pollen productivity in the middle of the dataset 371 upon ERV analysis with all seven taxa. Lastly, TCT is represented in pollen data at all sites 372 (unlike Abies, Alnus, or Quercus), and is present in vegetation close to the sampling pointcoring 373 site. aRSAP was estimated by plotting the likelihood scores for each distance across all taxa 374 combinations and pooling the results.

$376 \quad 3.7$ Distance weighting and estimation of $t R S A P$

377 AGL results were first averaged by the number of plots in each concentric ring and then each 378 ring was weighted using the Prentice-Sugita weighting under stable conditions, which affect 379 parameters $C_{z}$ and $n$ (Eq. 3, 3a). We assumed stable atmospheric conditions because simulation 380 experiments comparing unstable and stable models demonstrate little difference in estimated 381 aRSAP and pollen productivity (Broström et al. 2004). The pollen-specific fall speeds ( $\left.\mathrm{m} \mathrm{sec}^{-1}\right)$ 382 of Abies, Alnus, Pinus, Pseudotsuga, and Quercus have been determined in previous work (Table 383 S9). For TCT, Stoke's Law (Gregory 1973) was used to calculate fall speed using the average 384 grain size of each taxon and weighted by relative abundance of the contributing species Port385 Orford-cedar and incense-cedar (both Cupressaceae family). For subprolate grain 386 Notholithocarpus, major and minor axes were measured from reference slides in UC Berkeley's 387 collections, and then Stoke's Law with Falck's (1927) correction was used. Lastly, we 388 determined the coefficient of determination $\left(\mathrm{R}^{2}\right)$ of the linear model predicted from $\mathrm{AGL}_{\mathrm{dw}}$ at 
389 distance $\mathrm{z}\left(A G L_{d w_{z}}\right)$ as a function of PAR. The $\mathrm{R}^{2}$ between PAR and summed $\mathrm{AGL}_{\mathrm{dw}}$ for each

391 asymptote.

\section{$393 \quad 3.8$ PAR-biomass transfer equations}

394 We developed transfer equations to predict taxon-specific contributions to the distance-weighted 395 AGL $\left(\mathrm{AGL}_{\mathrm{dw}}\right)$ as a function of taxon-specific PAR. Although biomass "predicts" pollen 396 accumulation rates in a functional sense, our aim was to apply calibrated transfer functions to 397 predict biomass in the past. Consequently, we fitted regression lines with PAR values as the 398 independent variable. This reasoning has been used for needle accumulation rate as a predictor of 399 Holocene-era basal area (Blarquez et al. 2011).

400 In this analysis, each lake represented a sample with the depesitional-source area defined 401 by either aRSAP or tRSAP. We included seven pollen-producing taxa, namely Pseudotsuga, 402 Pinus, Notholithocarpus, TCT, Alnus, Quercus, and Abies, that collectively account for greater 403 than $99 \%$ of the pollen-producing trees present in the surrounding landscape. Using the assigned 404 source area distances, we calculated $\mathrm{AGL}_{\mathrm{dw}}$ for the taxa present at each lake and regressed it against PAR using linear models (see Fig. 8a,b). Specifically, we evaluated three model forms: a 406 linear model with an intercept term and slope term, a linear model with only a slope term, and 407 segmented linear model with one breakpoint. In the linear models with intercepts, the intercept 408 represents the "background" pollen component; because we treated PAR values as the 409 independent variable, these intercepts are negative. So, we included an origin-forced model as an 410 option because negative-intercept models are not biologically meaningful for biomass 411 reconstruction given that very low PAR values would yield negative biomass. We included the 
412 segmented model to potentially capture threshold responses in the relationship between AGL and

413 PAR (Muggeo 2008). We ranked the models by the Akaike Information Criterion for small

414 samples (AICc) in order to compare performance. AICc imposes a stronger penalty on model

415 complexity than AIC and was chosen in order to avoid fitting models which were overly

416 complex given the size of the dataset (Burnham and Anderson 2002).

417 To evaluate the uncertainty introduced by the PAR transfer functions, the $\mathrm{AGL}_{\mathrm{dw}}$ 418 predicted from PAR at each lake (predicted $A G L_{d w}$ ) was compared to the $A_{G L}$ calculated from 419 the observed $\mathrm{AGL}_{\mathrm{dw}}$. Error was propagated using a resampling method (Crowley et al. 1992).

420 Specifically, we estimated the error in predicted $\mathrm{AGL}_{\mathrm{dw}}$ for each iteration as a random sample 421 from a normal distribution with the mean equal to zero and the standard deviation equal to the 422 standard error of the regression estimate (SEE) for each taxon. Results were based on 10,000 423 iterations and reported as means and standard errors of the predicted $\mathrm{AGL}_{\mathrm{dw}}$ for each lake. Bias 424 between the predicted and observed $\mathrm{AGL}_{\mathrm{dw}}$ was calculated as:

$$
\text { Bias }=\frac{\text { Predicted } A G L_{d w}-\text { ObservedAGL } L_{d w}}{\text { Observed } A G L_{d w}}
$$

\section{4. Results}

\section{4.1 Chronology}

429 The seven lakes' chronologies were established using at least $20^{210} \mathrm{~Pb}$ dates-measurements at 430 each site (see Table S3-S9 for exact number of samples for each core). Blue Lake is shown as an 431 example (Fig. 4). The chronologies for Fish, North Twin, Ogaromtoc, Onion, Red Mountain, and 432 South Twin lakes followed the same procedure (Fig. S2). The lakes are characterized by rapid 433 sedimentation rates, with rates in the upper sediments in the range of $0.14-0.33 \mathrm{~cm} \mathrm{yr}^{-1}(3-7 \mathrm{yr}$ $434 \mathrm{~cm}^{-1}$ ). Therefore, surface samples (upper $0.5 \mathrm{~cm}$ ) contain pollen from 2018 (collection date) to 
4352011 at the oldest. Core lithology results are provided in the supplement (Figs. S3-4).

438 A group of highly abundant tree taxa contained Pseudotsuga, Pinus, Notholithocarpus, and TCT, 439 which were reflected in high $\left(>2,000\right.$ grains $\left.\mathrm{cm}^{-2} \mathrm{yr}^{-1}\right)$ PAR values in most samples (Fig. 5, 440 Table S10). For example, Pseudotsuga values were above 5,000 grains $\mathrm{cm}^{-2} \mathrm{yr}^{-1}$ at all sites 441 except Onion Lake. The highest overall PAR value was Pinus at Onion Lake which exceeded 44210,000 grains $\mathrm{cm}^{-2} \mathrm{yr}^{-1}$. High PAR values reflect the Douglas-fir and pine-dominant composition 443 of Six Rivers National Forest. Onion Lake is the only lake situated in the True Fir alliance zone 444 and, unsurprisingly, the Abies PAR value was the highest compared to all other sites $(5,000$ 445 grains $\mathrm{cm}^{-2} \mathrm{yr}^{-1}$ ). PAR values for Notholithocarpus and TCT varied across sites and were 446 between 1,000-4,000 grains $\mathrm{cm}^{-2} \mathrm{yr}^{-1}$.

447 The group of less abundant arboreal taxa included Alnus, Abies, and Quercus which were 448 present in most samples with PARs of less than 2,000 grains $\mathrm{cm}^{-2} \mathrm{yr}^{-1}$ (Fig. 5). Alnus values were 449 generally around 1,000 grains $\mathrm{cm}^{-2} \mathrm{yr}^{-1}$, although values above 2,000 grains $\mathrm{cm}^{-2} \mathrm{yr}^{-1}$ were 450 observed at Ogaromtoc and Fish Lakes. Abies values were low $\left(<1,000\right.$ grains $\left.\mathrm{cm}^{-2} \mathrm{yr}^{-1}\right)$ at all 451 sites except North Twin and Onion Lakes. Although pollen from Alnus, Abies, and Quercus were 452 found at all sites, the taxa themselves were not recorded from the transect sampling at several 453 lakes. This could be due to low abundance such that they were not captured in the survey or due 454 to their absence in the pellenshed sedimentary basin in which case their PAR contributions are 455 background deposition. Pollen from the "other hardwood" category (defined as willows, 456 buckthorn, hazel, and silk tassel) was detected in trace amounts $\left(<100\right.$ grains $\left.\mathrm{cm}^{-2} \mathrm{yr}^{-1}\right)$. 457 


\section{$458 \quad 4.3$ aRSAP and tRSAP}

459 Using the sub-setting approach for the aRSAP calculation, a coherent pattern was exhibited in 460 the likelihood function scores from model 3. The values were high at short distances and then 461 decreased rapidly until $175 \mathrm{~m}$ where they begin to flatten out. For all taxa combinations, we 462 inferred via visual inspection that the curves reached their asymptotes at a distance of $625 \mathrm{~m}$ and 463 thus the aRSAP of these lakes is $625 \mathrm{~m}$ from the lake shore. The likelihood function scores in 464 relation to the distance from the lake shore are shown for one of the three sub-set examples: 465 TCT, Pseudotsuga, and Pinus (Fig. 6). 466 Based on tRSAP calculations for the four dominant tree taxa, maximum $\mathrm{R}^{2}$ values were 467 reached before the maximum distance surveyed $\left(750 \mathrm{~m}\right.$ ) from the shoreline (Fig. 7). The $\mathrm{R}^{2}$ 468 values for Pinus and TCT were high (>0.75) at only $25 \mathrm{~m}$ from the shore and stabilized around $469225 \mathrm{~m}$, the tRSAP. The $\mathrm{R}^{2}$ values for Pseudotsuga and Notholithocarpus continued to improve 470 for some distance from the lake shore. For Pseudotsuga, the tRSAP was $625 \mathrm{~m}$; for 471 Notholithocarpus, it was $525 \mathrm{~m}$. Sample sizes were insufficient to estimate tRSAP values for the 472 minor taxa. For these taxa, we used the aRSAP value in $\mathrm{AGL}_{\mathrm{dw}}$ calculations (i.e., $625 \mathrm{~m}$ ).

475 PAR was a statistically meaningful and reasonably precise reliable-estimator of contemporary $476 \mathrm{AGL}_{\mathrm{dw}}$ for most of the pollen taxa present (Fig. 8). Based on the aRSAP distances, the linear 477 model without intercept was the best performing model $\left(\Delta \mathrm{AIC}_{\mathrm{c}}>4.0\right)$ for the four most 478 abundant taxa (Fig. 8a). For these taxa, the no-intercept regressions were not only significantly 479 better than the null model $(\mathrm{p}<0.001)$ but also explained most of the variation. $\mathrm{R}^{2}$ ranged from $480 \quad 0.87$ for TCT to 0.96 for Pseudotsuga (Table S11). The model results for the three less abundant 
81 species (i.e., Alnus, Abies and Quercus) were more complex (Fig. 8b). Based on $\triangle \mathrm{AIC}_{\mathrm{c}}$, the 482 segmented regression model best fit the Alnus and Abies data. However, both species were rare 483 and found in abundance at only one lake (Fig. 5). The existence of this one abundant point exerts 484 extraordinary leverage in the segmented regression. To avoid relying on a single point in these 485 two transfer functions, we used the second-best regression model. For Alnus, it was a linear 486 model; for Abies, it was a linear model without intercept (Table S11). For Quercus, none of the

\section{Discussion}

5035.1 Source areas of pollen: aRSAP and tRSAP 
504 Calibration of pollen-vegetation relationships is only effective when the scale of the vegetation

506 2004). Therefore, being able to specify the source area of pollen in a given basin is an important 507 step towards quantitative reconstruction of past vegetation (Sugita et al. 1999, Hellman et al. 508 2009). A primary aim of this work was to understand the spatial extent represented by the pollen 509 assemblage. We addressed this aim by determining the assemblage-level relevant source area of 510 pollen (aRSAP) obtained from pollen percentage data and ERV analysis and comparing those 511 estimates with the taxon-specific source area of pollen (tRSAP) for four main taxa. Both metrics 512 estimate the extent of vegetation that requires surveying for a subsequent reconstruction step but 513 are seldom compared.

514 aRSAP values have been estimated for lakes similar in size to those presented here (i.e., $515100 \mathrm{~m}$ radius), in different settings including simulated landscapes. Reported aRSAP values have 516 ranged from: $300 \mathrm{~m}$ in a simulation of a hemlock-hardwood forest in the US (Sugita 1994), to $517800-1,000 \mathrm{~m}$ in a simulation of spruce forest in Sweden (Sugita et al. 1999), to 1,700 $\mathrm{m}$ in 518 varying landcover types in Denmark (Nielsen and Sugita 2005), to 1,500-2,000 m in semi-boreal 519 forests of Estonia (Poska et al. 2011), and to 2,200 $\mathrm{m}$ in the upper Tibetan Plateau (Wang and 520 Herzschuh 2011). Within this list, all aRSAP estimates were derived from Prentice-Sugita-Sutton 521 distance-weighted models and are thus comparable to our estimate. Our aRSAP value of $625 \mathrm{~m}$ 522 falls in the range (300-2,200 m), though on the small end.

523 The aRSAP is unique to a given set of lakes and is sensitive to numerous factors such as 524 lake size and basin shape (Sugita 1993), vegetation patch size (Sugita 1994, Broström et al. 525 2005), vegetation patterns (Bunting et al. 2004), and taxa spatial distribution (Hellman et al. 526 2009). For example, aRSAP values tend to increase with landscape openness defined as the 
27 extent of the vegetation cover in the pollenshedsedimentary basin. For example, the aRSAP for 528 small ponds in a closed forest was simulated to be $300 \mathrm{~m}$ (Sugita 1994) and empirically verified 529 by Calcote (1995), whereas the aRSAP for small ponds in an open Swedish landscape was 1,000 $530 \mathrm{~m}$ (Sugita et al. 1999). However, expectations based on landscape openness can be complicated 531 by vegetation heterogeneity. Higher vegetation diversity and complex spatial distribution of taxa 532 are associated with larger aRSAPs (Hellman et al. 2009). The presence of rare taxa in a 533 landscape can also increase the aRSAP, other factors being held constant (Bunting et al. 2004). 534 For example, Commerford et al. (2013) observed the effect of rare taxa empirically: small lakes 535 in a 'very open' grassland in Kansas had a large aRSAP of 1,060 m, which they attributed to 536 scattered tree taxa in the tallgrass prairie.

537 The contemporary forests around our lake sites are dense, closed, and heavily dominated 538 by Douglas-fir (Skinner et al. 2018). Taxa like black oak (Quercus), white alder (Alnus), and 539 white fir (Abies) are present but not common. These rare taxa in the pollenshed area contributed 540 little to the overall biomass $(2.3 \%)$ but make the landscape more heterogeneous. This

541 heterogeneity can result in a larger aRSAP than if there were no rare taxa present. All else being 542 equal, longer distances from each sampling site are required to get a sufficient cover of all taxa 543 within the landscape to reach the regional average. These greater distances produce larger 544 aRSAP estimates (Hellman et al. 2009).

545 tRSAPs have been estimated at small lakes and ponds. For example, the tRSAP for Pinus 546 was $200 \mathrm{~m}$ from the lakeshore in southern-northeastern Germany (Matthias and Giesecke 2014), 547 and other tRSAP values in that study ranged from $50 \mathrm{~m}$ (Quercus) to $300 \mathrm{~m}$ (Fagus) to $1,000 \mathrm{~m}$ 548 (Betula). Jackson (1990) found small tRSAP estimates from ponds in New York: Acer $(<20 \mathrm{~m})$, 549 Betula $(>1,000 \mathrm{~m})$, Fagus $(>1,000 \mathrm{~m})$, Picea $(<100 \mathrm{~m})$, Quercus $(>1,000 \mathrm{~m})$ and Pinus/Tsuga 
$550(<500 \mathrm{~m})$. In this study, the tRSAP value for Pinus was $225 \mathrm{~m}$, a near match to Matthias and

551 Giesecke (2014) and comparable to Jackson (1990). The other tRSAP values in this study ranged

552 from $225 \mathrm{~m}$ (TCT) to $525 \mathrm{~m}$ (Notholithocarpus) to $625 \mathrm{~m}$ (Pseudotsuga). Like Matthias and

553 Giesecke's results, the tRSAPs are inconsistent with expectations based solely on the respective

554 fall speeds of the taxa. For example, Pinus has one of the assemblage's lowest fall speeds and

555 was expected to travel longer distances and have a large tRSAP; in fact, it had one of the shortest 556 tRSAPs.

557 Unexpectedly small source areas of highly dispersible taxa have been observed in 558 simulated landscapes (e.g., Betula, Sugita 1994) and have been attributed to vegetation

559 patterning. The estimated RSAP reflects the minimum distance at which the regional vegetation

560 composition is attained. For example, if Betula is uniformly spread in a forest, the regional

561 distribution signal of Betula will be captured closer to the sampling point than in a forest where

562 Betula is heterogeneously spread across the forest When a taxon has a relatively homogeneous

563 distribution across the landscape (e.g., found in all communities with small patch size, occurs

564 frequently as individuals in all communities), the regional distribution of the taxon is attained 
573 dominant overstory could effectively shrink the tRSAPs of Pinus and TCT, following the logic

575 despite their fall speeds, and relatively large tRSAPs for Pseudotsuga and Notholithocarpus, 576 aligns with the study area's vegetation patterning.

Our estimated aRSAP (625 m) and tRSAP values (all $625 \mathrm{~m}$ or less) suggest consistent, 578 though not identical, interpretations of the pollenshedsource area of pollen. Both estimates 579 indicate that the pollen record "senses" a local view of about the same area of the surrounding 580 vegetation. Given that vegetation surveying must meet or exceed the scale of the relevant source 581 area of pollen for quantitative reconstruction (Bunting et al. 2004), vastly different aRSAP and 582 tRSAP estimates would potentially be consequential. If, for example, we had estimated an 583 aRSAP $<<$ tRSAP, it would imply that our assemblage-level view was in some way blind to taxa 584 in the assemblage, and thus missing important landscape patterning or other features of the 585 pollenshedarea from which pollen originated. On the other hand, if we had estimated an aRSAP $586>$ tRSAP, it would imply the subsequent reconstruction represents a larger area than is 587 potentially being recorded by the pollen system.

This consistency between the aRSAP and tRSAP results was reflected in the similarity of 589 the $\mathrm{AGL}_{\mathrm{dw}}$ reconstructions (Table $\underline{3} z$, Table $3 \underline{4}$ ). On average, observed $\mathrm{AGL}_{\mathrm{dw}}$ for each lake was $590 \quad 10.1 \mathrm{Mg} \mathrm{ha}^{-1}(5.2 \%)$ larger using aRSAP with the differences ranging from $2.6 \mathrm{Mg} \mathrm{ha}^{-1}(1.1 \%)$

591 larger at North Twin Lake to $22.2 \mathrm{Mg} \mathrm{ha}^{-1}(10.3 \%)$ larger at Onion Lake. The differences in 592 terms of predictive ability were equally modest with aRSAP estimates producing somewhat more 593 accurate and less biased results. 
596 Establishing the relationship between contemporary biomass and modern PAR values is 597 contingent upon obtaining accurate sedimentation rates in cores. We are confident in our 598 estimated sedimentation rates for two key reasons. First, we used a state of the art, robust 599 Bayesian model to develop age models from ${ }^{210} \mathrm{~Pb}$ dates (Aquino-López et al. 2018). Our results 600 showed low uncertainty in the modeled ages in all cores, particularly in the top $20 \mathrm{~cm}$. Second, 601 we were able to compare our upper sedimentation rates representing the last decade to estimates 602 from two of the same lakes (Ogaromtoc and Fish lakes) that were collected in 2008 and 2009 603 (Crawford et al. 2015). We found similar sedimentation rates in the upper sediments: 2.0-4.0 mm $604 \mathrm{yr}^{-1}$ compared to $2.0-3.3 \mathrm{~mm} \mathrm{yr}^{-1}$. Our modern PAR values are also in agreement with PAR 605 values from the youngest sediments in Crawford et al. (2015).

606 The ultimate goal of this research was to assess whether PAR be used to predict distance-

607 weighted biomass for major tree taxa in the Klamath area, and therefore generate models suitable 608 for reconstruction of past biomass dynamics. The fact that contemporary pollen influx is a

609 reasonably reliableprecise predictor of contemporary distance-weighted AGL at these sites 610 suggests that PAR can be used to infer changes in plant biomass at for these sites. But even with 611 apparently statistically sound modern models, it may not be reasonable to apply the models for 612 reconstruction in all contexts.

613 In an ideal situation, the calibration dataset would include sites with a wide range of 614 population sizes of the main taxa to allow any time in the fossil record to be reconstructed. Our 615 model had less skill in estimating low levels of forest biomass because we were unable to find 616 lake sites that met our selection criteria and supported sparse forest cover. Other modern 617 quantitative vegetation reconstruction models have been restricted at the upper end of the 618 calibration. Trees growing in dense forest stands produce less pollen than an exposed tree in a 
619 field, which suggests that increased forest density could result in reduced net pollen productivity

621 (2011) found that the relationship between needle accumulation rate and forest basal area tended 622 to saturate above $40 \mathrm{~m}^{2} \mathrm{ha}^{-1}$ for conifer-dominated sites. However, despite the high biomass623 density of the contemporary forest at our sites (Knight et al. 2020), there was no evidence of 624 saturation in the PAR-biomass functions for the major taxa. Even at the maximum PAR values, 625 the biomass values increase at pace following the log-linear fits (Fig. 8a).

626 Long-term PAR records from lakes in the area provide insight into time periods where 627 our calibrated models will be able to capture past conditions. Comparable taxa-specific PAR 628 values from lake sites in the region were only available for Pinus, and they suggest time periods 629 of agreement with our Pinus PAR measurements and our total Pinus PAR-AGL model, which 630 covers a range between 1,500 and 11,000 grains $\mathrm{cm}^{-2} \mathrm{yr}^{-1}$. For example, Briles et al. (2008) 631 reported Pinus PAR between 2,000 and 8,000 grains $\mathrm{cm}^{-2} \mathrm{yr}^{-1}$ at Sanger Lake in the western 632 Klamath Mountains over 15,000 years BP. Likewise, a 3,000-year PAR record from Fish Lake (a 633 lake also examined in this study) shows agreement with our total Pinus PAR range during some 634 time periods. Fish Lake's record shows temporal variability intat Pinus PAR values between 6352,000 to 9,000 grains $\mathrm{cm}^{-2} \mathrm{yr}^{-1}$ during the last two hundred years (Crawford et al. 2015), which 636 falls within our calibration. Lastly, total PAR values measured at eight lakes in the Klamath area 637 since $15,000 \mathrm{BP}$ range from 2,000 to 15,000 grains $\mathrm{cm}^{-2} \mathrm{yr}^{-1}$ (Briles et al. 2011) and are similar 638 in size to lakes in this study and have a dense surrounding forest, although they are located in the 639 white-fir vegetation zone.

640 In addition to selecting a range of forest conditions, researchers undertaking similar 641 efforts will need to consider the number of lakes needed for statistical soundness for the 
642 calibration. The seven lakes presented here appear to have been sufficient to build robust models

643 in terms of low coefficient of variation (Table $2 \underline{3}$ ), but it may be difficult in other locations to 644 find enough suitable lakes using consistent selection criteria. If reconstructions of continuous 645 Holocene-length biomass records are sought, using a high number of lakes has the downside of 646 great expense (from isotopic dating) and labor (from pollen counting), unless accurate automatic 647 classification systems become widespread (Sevillano et al. 2020).

648 The calibration step we undertook required modern biomass data, which may be difficult 649 to obtain empirically for a large number of lakes or in settings with challenging topography. For 650 example, transects in this study ran $750 \mathrm{~m}$ from the shoreline, but steep topography and scree 651 slopes occasionally prevented a complete survey. Because we studied small lakes and needed 652 finely resolved biomass data, sparse inventory data with large geographic extent (e.g., FIA data) 653 were not an appropriate substitute for field surveys. However, FIA data provided essential 654 information regarding the basal area to biomass relationships for the common tree species in the 655 region (Table S8).

$656 \quad 5.3$ Limitations of PAR and PVMs

657 Our results show the utility of calibrated PAR-AGL models for this study, and we have provided 658 a robust process for including uncertainty in PAR-AGL models. However, PAR itself may vary 659 in ways that reduce its value for pollen-based reconstructions in all landscapes. For instance, net 660 pollen deposition can vary spatially and temporally if sediment focusing or pollen redeposition 661 occurs. While studies investigating PAR from modern sedimentary records did not find that 662 redeposition and sediment focusing affected PAR (Seppä and Hicks, 2006; Giesecke and

663 Fontana, 2008), other studies have documented the influence of these factors on PAR (Davis et 664 al. 1984, Odgaard 1993, Matthias and Giesecke 2014). Additionally, between-lake differences in 
665 PAR values can arise from differences in pollen taphonomy due to basin size or stream inflow

$p$

$\underline{\text { Giesecke 2014). Without long-term pollen monitoring studies across different biomes and }}$ accompanying detailed biomass data, true data validation will not be possible.

\section{$\underline{\text { Pollen transport in mountain environments has been studied in Europe through the European }}$}

$\underline{\text { Pollen Monitoring Programme, but, to our knowledge, has not been studied in the mountains of }}$ $\underline{\text { western North America outside of the present work. Several pollen monitoring studies with }}$ $\underline{\text { transects running through multiple vegetation zones in mountainous areas tend to show that }}$ pollen from lower forest zones is quite abundant in upper zones, and this effect appears more pronounced when high altitude zones have lower productivity (e.g., the Rila Mountains in Bulgaria, Tonkov et al. 2001). Unlike mountain transect studies, our sites are all within one vegetation zone, therefore reducing the significance of these effects, and we are not studying tree $\underline{\text { line position. The Douglas-fir dominated conifer forest in the Klamath Mountain is a relatively }}$ $\underline{\text { high productivity zone, and such zones typically show less of an "uphill" effect that impacts tree- }}$ line pollen assemblages (e.g., Swiss Alps tree line study, Sjögren et al. 2008)."

All PVMs, including PAR-biomass transfer functions, are based on assumptions that may not hold in a changing landscape. It must be assumed, for example, that taphonomic processes filtering pollen in lake sediments are constant over time and among lakes, unless taphonomic biases are precisely quantified (Allison and Bottjer 2011). Using our method, quantitative

687 biomass reconstruction would also assume that the relevant source area of pollen is constant over transport for Reviewer 2. 
688 time. We estimated the aRSAP of our seven sites as well as the tRSAP of abundant taxa, but 689 these may apply to a landscape arrangement which is unique in the last 3,000 years. The present690 day high PAR values of Pseudotsuga are not replicated in the fossil pollen record at any other 691 time in three millennia (Crawford et al. 2015), suggesting that the dominance of shade tolerant 692 Pseudotsuga is also not found elsewhere in this time period. Deep-time reconstructions from 693 lakes in this study have shown large changes in vegetation composition due to climate, Native 694 land-use, fire disturbances, and, in the last century, fire suppression. In response, we anticipate 695 that the relevant source areas of pollen will expand and contract over time. Because the spatial 696 patterns of past vegetation are usually unknown, it is difficult to estimate past relevant pollen 697 sources areas. However, the Multiple Scenario Approach (MSA, Bunting and Middleton 2009) 698 offers insight on this issue. Under MSA, hypothetical landscapes are created via rules for plant 699 placement and environmental parameters, and then pollen assemblages are simulated and 700 compared to known pollen signals to identify probable past vegetation mosaics. Another 701 experimental method to estimate past relevant pollen source area has been explored through 702 modeling (Hellman et al. 2009) where regional vegetation composition and available pollen 703 productivity estimates are available for multiple sites (Sugita 2007b). Hellman et al.'s (2009) 704 simulations suggest relatively robust aRSAP estimates of 1,000 to $2,500 \mathrm{~m}$ for small lakes under 705 hypothetical landscapes from southern Sweden where natural and anthropogenic disturbances 706 have occurred during the Holocene. Such simulations provide a means to test the potential 707 robustness of aRSAP in the Klamath area. 
10 Although methodologically challenging, calibrating PAR-biomass models is an important step

711 towards quantitative reconstruction of past vegetation. Our calibration steps included estimating

712 the spatial extent represented by the pollen system, comparing two estimates of the

713 pollenshedRSAP, and evaluating PAR-AGL models. We found comparable aRSAP and tRSAP

714 estimates that aligned with expectations given the modern forest's dense, closed conditions. We

715 also demonstrated that PARs of major tree taxa derived from lake sediments are linearly related 716 to distance-weighted AGL, and our PAR-AGL ${ }_{\mathrm{dw}}$ models accurately reconstruct modern lake-

717 surrounding biomass. According to PAR values from local and regional lakes sites, our modern 718 models are broad enough to capture a range of forest structures over the last 15,000 years BP.

719 We therefore conclude that our results prove the utility of calibrated PAR-AGL models for 720 quantitative reconstruction of past vegetation. 


\section{References}

723 Allison P and Bottjer DJ (2011) Taphonomy: Bias and process through time. In: Allison PA and

Andersen ST (1970) The relative pollen productivity and pollen representation of north European trees, and correction factors for tree pollen spectra. Danmarks geologiske Undersogelse 96:1-99.

Appleby P and Oldfield F (1978) The calculation of lead-210 dates assuming a constant rate of supply of unsupported $210 \mathrm{~Pb}$ to the sediment. Catena $5: 1-8$.

Aquino-López MA, Blaauw J, Christen A, and Sanderson NK (2018) Bayesian Analysis of 210$\mathrm{Pb}$ Dating. Journal of Agricultural, Biological, and Environmental Studies 23:317-333.

Blaauw M and Christen JA (2011) Flexible paleoclimate age-depth models using an autoregressive gamma process. Bayesian Analysis 6:457-474.

Baskaran M, Miller CJ, Kumar A et al. (2015) Sediment aceumulation rates and sediment dynamies using five different methods in a well constrained impoundment: Case study from Union Lake, Michigan. Journal of Great Lakes Research 41:607 617.

Bennett KD (1983) Postglacial population expansion of forest trees in Norfolk, UK. Nature 303: $164-67$.

Bennett KD (1986) The rate of spread and population increase of forest trees during the postglacial. Philosophical Transactions of the Royal Society of London, Series B 314:523-531. 
743 Blarquez O, Carcaillet C, Elzein TM et al. (2011) Needle accumulation rate model-based reconstruction of paleo-tree biomass in the western subalpine Alps. The Holocene 22:579-587.

Briles CE, Whitlock C, and Bartlein PJ (2005) Postglacial vegetation, fire, and climate history of the Siskiyou Mountains, Oregon, USA. Quaternary Research 64:44-56. 
765 Bunting MJ, Armitage R, Binney HA et al. (2005) Estimates of 'relative pollen productivity' and 'relevant source area of pollen' for major tree taxa in two Norfolk (UK)

Bunting MJ and Middleton R (2009) The Multiple Scenario Approach: a pragmatic method for past vegetation mosaic reconstruction. The Holocene 19:799-803.

Bunting MJ and Hjelle KL (2010) Effect of vegetation data collection strategies on estimates of relevant source area of pollen (RSAP) and relative pollen productivity estimates (relative PPE) for non-arboreal taxa. Vegetation History and Archaeobotany 19:365-374.

Bunting MJ, Farrell M, Broström A et al. (2013) Palynological perspectives on vegetation survey: a critical step for model-based reconstruction of Quaternary land cover. Quaternary Science Reviews 82:41-55.

Burnham KP and Anderson DR (2002) Model selection and multimodel inference: a practical information-theoretic approach. New York: Springer-Verlag.

Calcote R (1995) Pollen source area and pollen productivity: evidence from forest hollows. Journal of Ecology 83:591-602.

Cheng STE (2004) Forest Service Research Natural Areas in California. General Technical Report PSW-GTR-188. Pacific Southwest Research Station, Forest Service, U.S. Department of Agriculture, Albany, CA. 
787 Christen JA and Fox C (2010) A general purpose sampling algorithm for continuous distributions (the t-walk). Bayesian Analysis 5:263-281.

Colombaroli D and Gavin DG (2010) Highly episodic fire and erosion regime over the past 2,000 years in the Siskiyou Mountains, Oregon. Proceedings of the National Academy of Sciences 107:18909-18914.

792 Commerford JL, McLauchlan KK and Sugita S (2013) Calibrating vegetation cover and grassland pollen assemblages in the Flint Hills of Kansas, USA. American Journal of Plant Sciences 4:1-10.

Crawford JN, Mensing SA, Lake FK et al. (2015) Late Holocene fire and vegetation reconstruction from the western Klamath Mountains, California, USA: A multidisciplinary approach for examining potential human land-use impacts. The Holocene 25:1341-1357.

Crowley PH (1992) Resampling methods for computation-intensive data analysis in ecology and evolution. Annual Review of Ecological Systems 23:405-447.

Daniels ML, Anderson RS and Whitlock C (2005) Vegetation and fire history since the Late Pleistocene from the Trinity Mountains, northwestern California, USA. The Holocene 15:1062-1071.

804 Davis MB (1963) On the theory of pollen analysis. American Journal of Science 261:897-912.

805 Davis MB (1967b) Pollen deposition in lakes as measured by sediment traps. Geological Society $806 \quad$ of America Bulletin 78: 849-58.

807 Davis MB and Deevey ES (1964) Pollen accumulation rates: estimates from Late-Glacial 808 sediment Rogers Lake. Science 145:1293-1295. 
809 Davis MB, Brubaker LB and Webb T (1973) Calibration of absolute pollen influx. In: Birks HJB and Lund JWG (eds) Lake sediments and environmental history. Minneapolis: University of Minnesota Press, pp.261-93.

Davis MB (2000) Palynology after Y2K: Understanding the source area of pollen in sediments. Annual Review of Earth Planetary Sciences 28:1-18.

\section{Dawson A, Paciorek CJ, Goring SJ, Jackson ST, McLachlan JS, Williams JW (2019)}

Quantifying trends and uncertainty in prehistoric forest composition in the upper Midwestern United States Ecology 100(12):1-18.

Doher LI (1980) Palynomorph preparation procedures currently used in the paleontology and stratigraphy laboratories. U.S. Geological Survey Circular 830:1-28.

Fægri K and Iversen J (1989) Textbook of Pollen Analysis. New York: Haffner Press.

Fagerlind F (1952) The real significance of pollen diagrams. Botaniska Notiser 105:185-224.

Feldman R, Tomback DF and Koehler J (1999) Cost of mutualism: competition, tree morphology, and pollen production in limber pine clusters. Ecology 80:324-329.

FIADB (2020) Forest Inventory and Analysis Database version 1.8.0.0.1.

\section{https://apps.fs.usda.gov/fia/datamart/datamart.html}

Gaillard M-J, Sugita S, Broström A et al. (2000) Long term land-cover changes on regional to global scales inferred from fossil pollen - how to meet the challenges of climate research? Pages Newsletter 8:30-32. 
Gaillard M-J, Sugita S, Mazier F et al. (2010) Holocene land-cover reconstructions for studies on land cover-climate feedbacks. Climate of the Past 6:483-499.

Giesecke T (2005) Moving front or population expansion: how did Picea abies (L.) Karst.

Han Y, Liu H, Hao Q et al. (2017) More reliable pollen productivity estimates and relative source area of pollen in a forest-steppe ecotone with improved vegetation survey. The Holocene 27:1567-1577.

Hellman S, Gaillard MJ, Broström A et al. (2008a) The REVEALS model, a new tool to estimate past regional plant abundance from data in large lakes: validation in southern Sweden. Journal of Quaternary Science 23:21-42.

Hellman S, Broström A, Gaillard MJ et al. (2008b) Effects of the sampling design and selection of parameter values on pollen based quantitative reconstructions of regional vegetation: a case study in southern Sweden using the REVEALS model. Vegetation Historical Archaeobotany 17:445-460.

Hellman S, Bunting MJ and Gaillard M-J (2009) Relevant Source Area of Pollen in patchy cultural landscapes and signals of anthropogenic landscape disturbance in the pollen record: A simulation approach. Review of Palaeobotany and Palynology $153: 245-258$. 
854 Hicks, S. and Hyvarinen, H. 1999: Pollen influx values measured in different sedimentary environments and their palaeoecological implications. Grana 38:228-42.

856 Hicks S (2001) The use of annual arboreal pollen deposition values for delimiting tree-lines in 857 the landscape and exploring models of pollen dispersal. Review of Palaeobotany and Palynology 117:1-29.

859 Hicks S (2006) When no pollen does not mean no trees. Vegetation History and Archeobotany $\underline{15: 253-261 .}$ 860 861 Hickman JC (1993) The Jepson manual: higher plants of California. Berkeley: University of 862 California Press.

863 Hudiburg T, Law B, Turner DP et al. (2009) Carbon dynamics of Oregon and Northern California forests and potential land-based carbon storage. Ecological 865 Applications 19:163-180.

Hyvärinen H (1975) Absolute and relative pollen diagrams from northernmost Fennoscandia. Fennia 142:1-23.

868 Irwin WP (1981) Tectonic accretion of the Klamath Mountains. In: Ernst WG (ed) The

Geotectonic Development of California. Englewood Cliffs: Prentice Hall, pp.2949.

871 Jackson ST (1990) Pollen Source Area and Representation in Small Lakes of the Northeastern 872 United States. Review of Palaeobotany and Palynology 63:53-76.

873 Jweda J and Baskaran M (2011) Intercennected riverine lacustrine systems as sedimentary 874 
Knight CA, Cogbill CV, Potts MD et al. (2020) Settlement-era forest structure and composition in the Klamath Mountains: Reconstructing a historical baseline. Ecosphere 11:e03250.

880 Likens GE and Davis MB (1975) Post-glacial History of Mirror Lake and its Watershed in New 881 Hampshire: an Initial Report. Internationale Vereinigung für Theoretische und 882 Angewandte Limnologie 19:982-993.

883 MacDonald GM (1993) Fossil pollen analysis and the reconstruction of plant invasions. $884 \quad$ Advances in Ecological Research 24:67-109.

885 Marquer L, Gaillard M-J, Sugita S et al. (2014) Holocene changes in vegetation composition in northern Europe: why quantitative pollen-based vegetation reconstructions matter. Quaternary Science Reviews 90:199-216.

888 Matthias I and Giesecke T (2014) Insights into pollen source area, transport and deposition from modern pollen accumulation rates in lake sediments. Quaternary Science Reviews $87: 12-23$.

Mohr JA, Whitlock C and Skinner CN (2000) Postglacial vegetation and fire history, eastern Klamath Mountains, California. The Holocene 10:587-601.

893 Morris JL, DeRose JR and Brunelle AR (2015) Long-term landscape changes in a subalpine spruce-fir forest in central Utah, USA. Forest Ecosystems 2:1-12.

895 Muggeo VM (2008) Segmented: an R package to fit regression models with broken-line $896 \quad$ relationships. $R$ News 8:20-25.

897 Nielsen AB and Sugita S (2005) Estimating Relevant Source Area of Pollen for Small Danish 898 Lakes around AD 1800. The Holocene 15:1006-1020. 
899 Odgaard BV (1993) Wind-determined sediment distribution and Holocene sediment yield in a

901 Parsons R and Prentice IC (1981) Statistical approaches to R-values and the pollen vegetation 902 relationship. Review of Palaeobotany and Palynology 32:127-152.

903 Poska A, Meltsov V, Sugita S et al. (2011) Relative pollen productivity estimates of major 904 anemophilous taxa and relevant source area of pollen in a cultural landscape of $167: 30-39$.

Prentice IC (1985) Pollen representation, source area, and basin size: towards a unified theory of pollen analysis. Quaternary Research 23:76-86.

Prentice IC (1988) Records of vegetation in time and space: the principles of pollen analysis. In: Huntley B and Webb T III (eds) Vegetation history. Dordrecht: Kluwer Academic Publishers, pp.17-42.

Ritchie JC (1969) Absolute pollen frequencies and carbon-14 age of Holocene lake sediment from the Riding Mountain area of Manitoba. Canadian Journal of Botany 47: $1345-1349$.

Sawyer JO and Thornburg DA (1977) Montane and subalpine vegetation of the Klamath Mountains. In: Barbour MG and Major J (eds) Terrestrial Vegetation of California. Berkeley: California Native Plant Society, pp.699-732.

Sevillano V, Holt K and Aznarte JL (2020) Precise automatic classification of 46 different pollen types with convolutional neural networks. PLoS ONE 15:e0229751. 
920 Seppä H and Hicks S (2006) Integration of modern and past pollen accumulation rate (PAR)

records across the arctic tree-line: a method for more precise vegetation reconstructions. Quaternary Science Review 25:1501-1516. 
961 Tonkova S, Hicks S, Bozilovaa E, Atanassova J (2001) Pollen monitoring in the central Rila

$962 \quad$ Mountains, Southwestern Bulgaria: comparisons between pollen traps and surface 963

BE (eds) Quantification of land surfaces cleared of forests during the Holocene modern pollen/vegetation/landscape relationships as an aid to the interpretation of fossil pollen data. Gustav Fischer Verlag, pp.1-18.

Sugita S, Gaillard M-J and Broström A (1999) Landscape openness and pollen records: a simulation approach. The Holocene 9:409-421.

Sugita S (2007a) Theory of quantitative reconstruction of vegetation I: Pollen from large sites REVEALS regional vegetation composition. The Holocene 17:229-241.

Sugita S (2007b) Theory of quantitative reconstruction of vegetation II: All you need is LOVE. The Holocene 17:243-257.

Sutton OG (1947) The problem of diffusion in the lower atmosphere. Quarterly Journal of the Royal Meteorological Society 73: 257-276.

Sutton OG (1953) Micrometeorology. New York: McGraw-Hill.

Swetnam TW, Allen CD and Betancourt JL (1999) Applied historical ecology: Using the past to manage for the future. Ecological Applications 9:1189-1206.

Taylor AH and Skinner CN (2003) Spatial patterns and controls on historical fire regimes and forest structure in the Klamath Mountains. Ecological Applications 13:704-719.

Theuerkauf M, Kuparinen A and Joosten H (2012) Pollen productivity estimates strongly depend on assumed pollen dispersal. The Holocene 23: 14-24. samples for the period 1993 \pm 1999 . Review of Palaeobotany and Palynology

\section{7:167-182.}


965 United States Department of Agriculture, Forest Service (2000) Timber Cruising Handbook and

967 Von Post L (1918) Skogsträdpollen i sydsvenska torvmosselagerföljder. In: Forhandlinger ved de 968 skandinaviske naturforskeres 16. Møte i Kristiania den 10-15. Juli 1916.

970 Wahrhaftig C and Birman JH (1965) The Quaternary of the Pacific mountain system in

California. In: HE Wright and Frey DG (eds) Quaternary of the United States.

Princeton: Princeton University Press, pp.299-341.

973 Wang Y and Herzschuh U (2011) Reassessment of Holocene vegetation change on the upper

Tibetan Plateau using the pollen-based REVEALS model. Review of

Palaeobotany and Palynology 168:31-40.

976 Wanket J (2002) Late Quaternary vegetation and climate of the Klamath Mountains. PhD

Dissertation, University of California, Berkeley, USA.

978 Whittaker RH (1960) Vegetation of the Siskiyou Mountains, Oregon and California. Ecological 979 Monographs 30:279-338.

980 Zhou X and Hemstrom MA (2009) Estimating aboveground tree biomass on forest land in the of Agriculture, Forest Service, Pacific Northwest Research Station. 


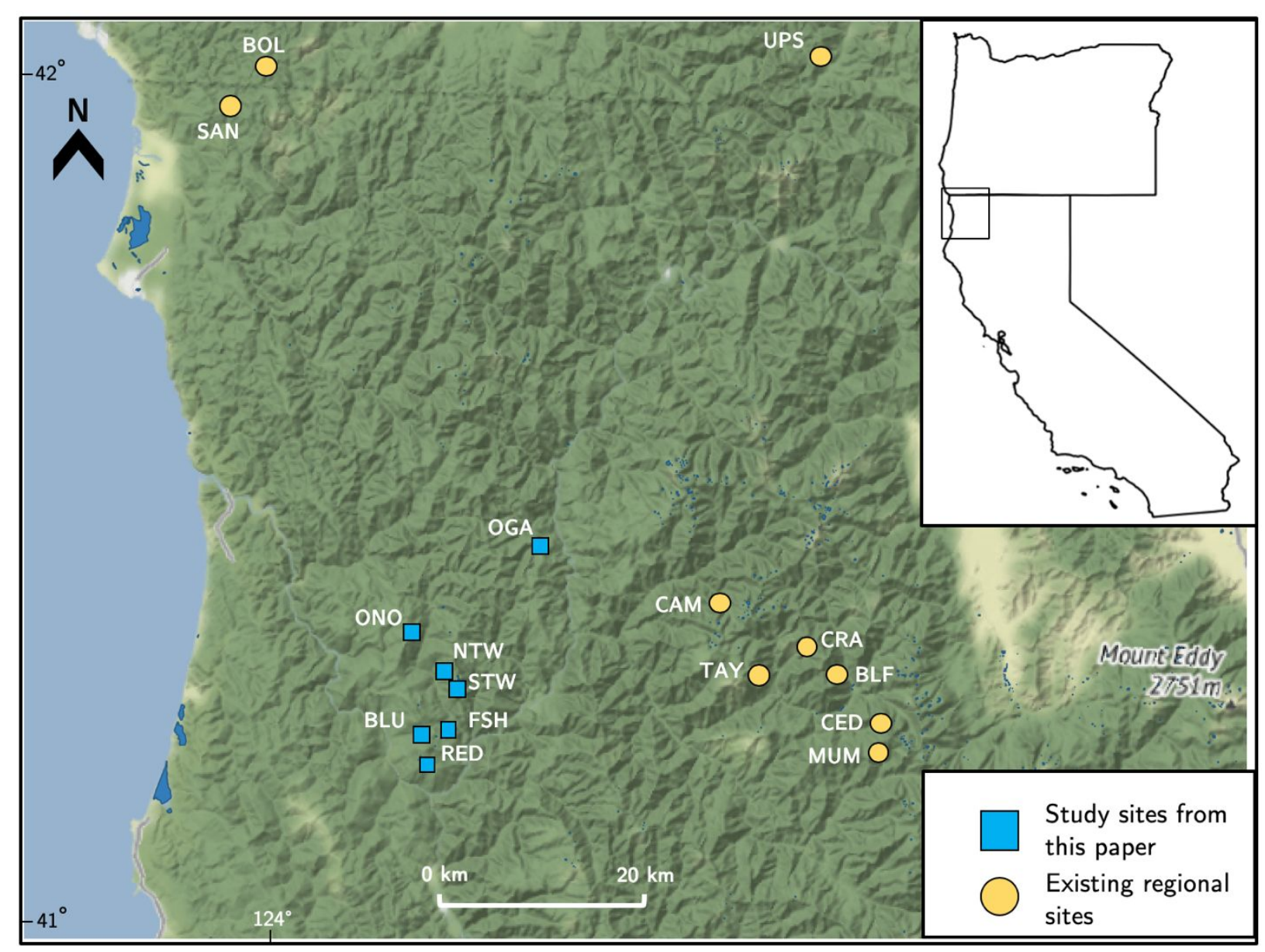

Figure 1. Map shows study sites (blue squares) in northwestern California: Blue Lake (BLU), Fish Lake (FSH), North Twin Lake (NTW), Lake Ogaromtoc (OGA), Onion Lake (ONO), Red Mountain Lake (RED), and South Twin Lake (STW). Note that Lake Ogaromtoc and Fish Lake were described in Crawford et al. (2015) and North and South Twin Lake were described in Wanket (2002) but were also studied in this project. Map also shows Holocene-era pollen records from other parts of the region (yellow circles): Bluff (BLF) and Crater (CRA) Lakes (Mohr et al. 2000); Sanger (SAN) and Bolan (BOL) Lakes (Briles et al. 2008); Upper Squaw Lake (USL; Colombaroli and Gavin 2010); Mumbo (MUM) Lake (Daniels et al. 2005); and Campbell (CAM), Taylor (TAY), and Cedar (CED) Lakes (Briles et al. 2011). 


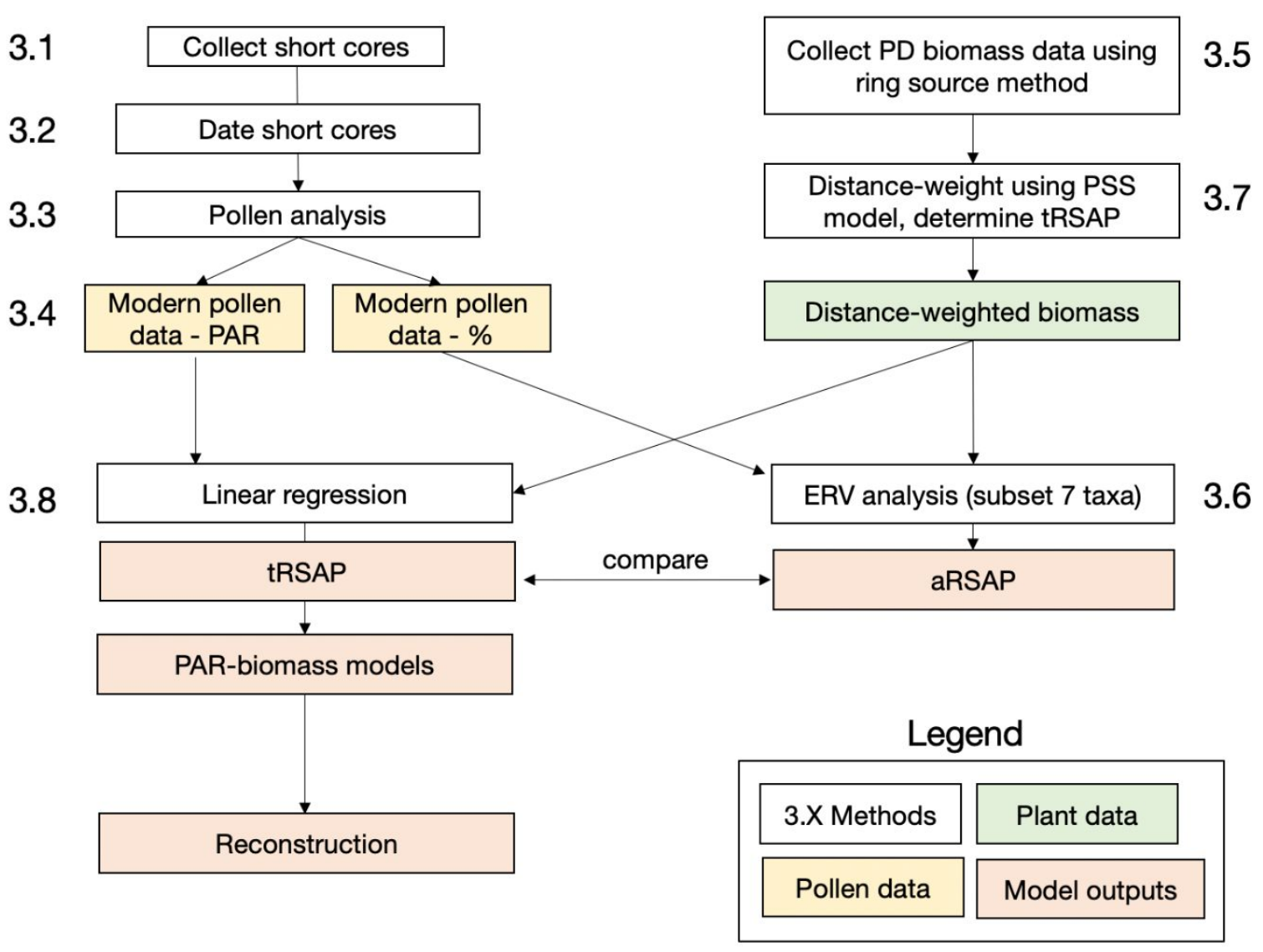

Figure 2. Flowchart of methodological steps leading to a calibrated PAR-biomass model. 
Figure 3. A schematic of the vegetation survey design (not to scale), following Han et al. (2017), that included eight transect lines along the cardinal and sub-cardinal directions where sampling occurred at the mid-point of each concentric ring (the schematic shows an example with only four rings). Sample locations (squares) are shown on the north transect for illustration. 
b)

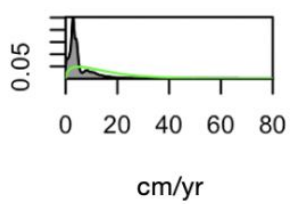

c) Supported ${ }^{210} \mathrm{~Pb}$

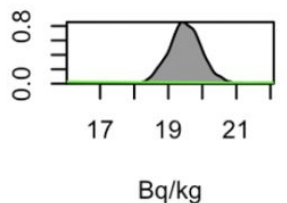

d) Supply ${ }^{210} \mathrm{~Pb}$

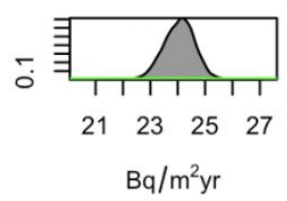

Blue Lake

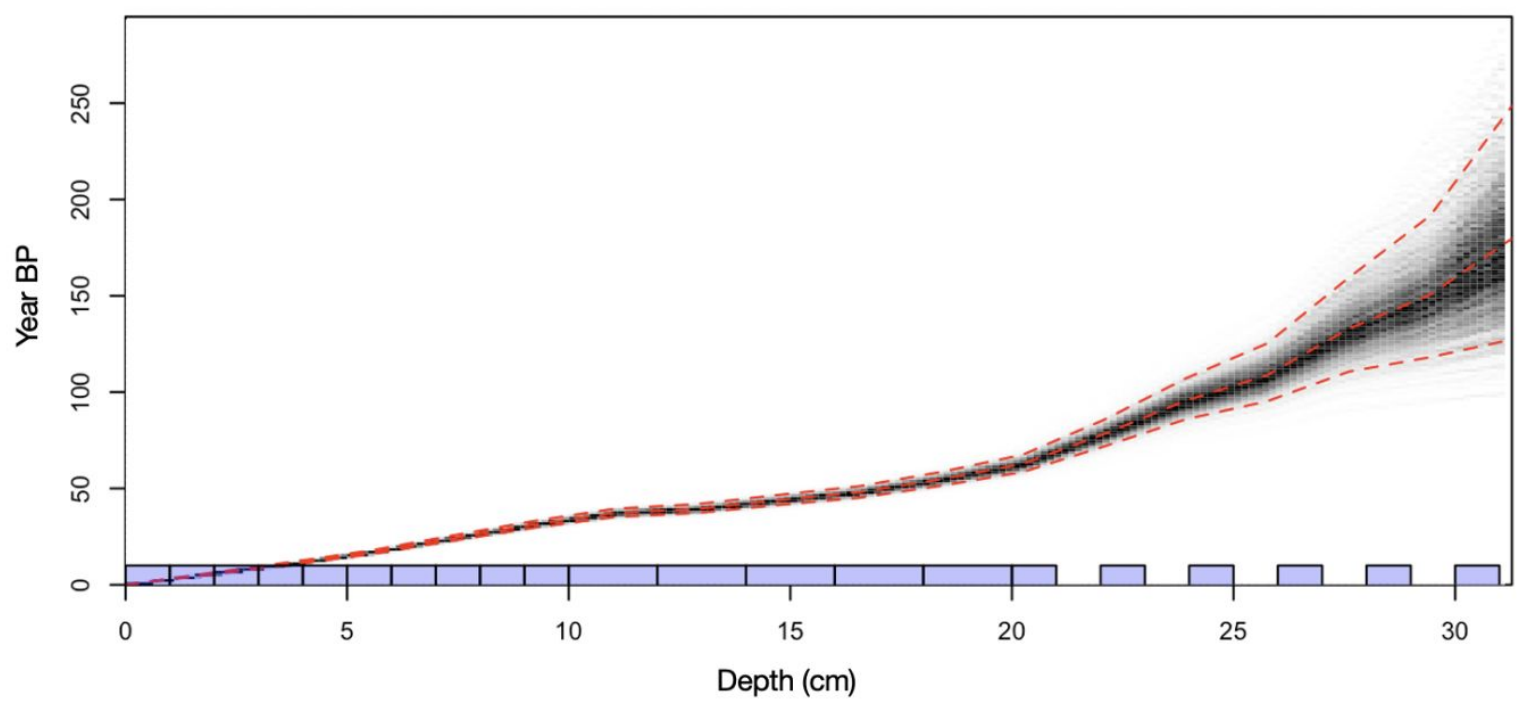

Figure 4. Example of Pb-210 age model construction. The age-to-depth results of the Plum modeling for Blue Lake. The grey lines are simulation from Plum and the dashed red lines represent the mean age and the $95 \%$ interval. The small panels at the top show the prior (green) and posterior (grey) distributions for (a) the memory $(\omega)$, which describes the coherence in sedimentation rates along the core (b) the sedimentation rate $(\alpha)$, (c) the supported ${ }^{210} \mathrm{~Pb}\left(\mathrm{P}^{\mathrm{S}}\right)$, which is the background level of ${ }^{210} \mathrm{~Pb}$ already present in the sediment, and (d) and the supply of ${ }^{210} \mathrm{~Pb}(\Phi)$. For other sites, see Supplementary Information. 

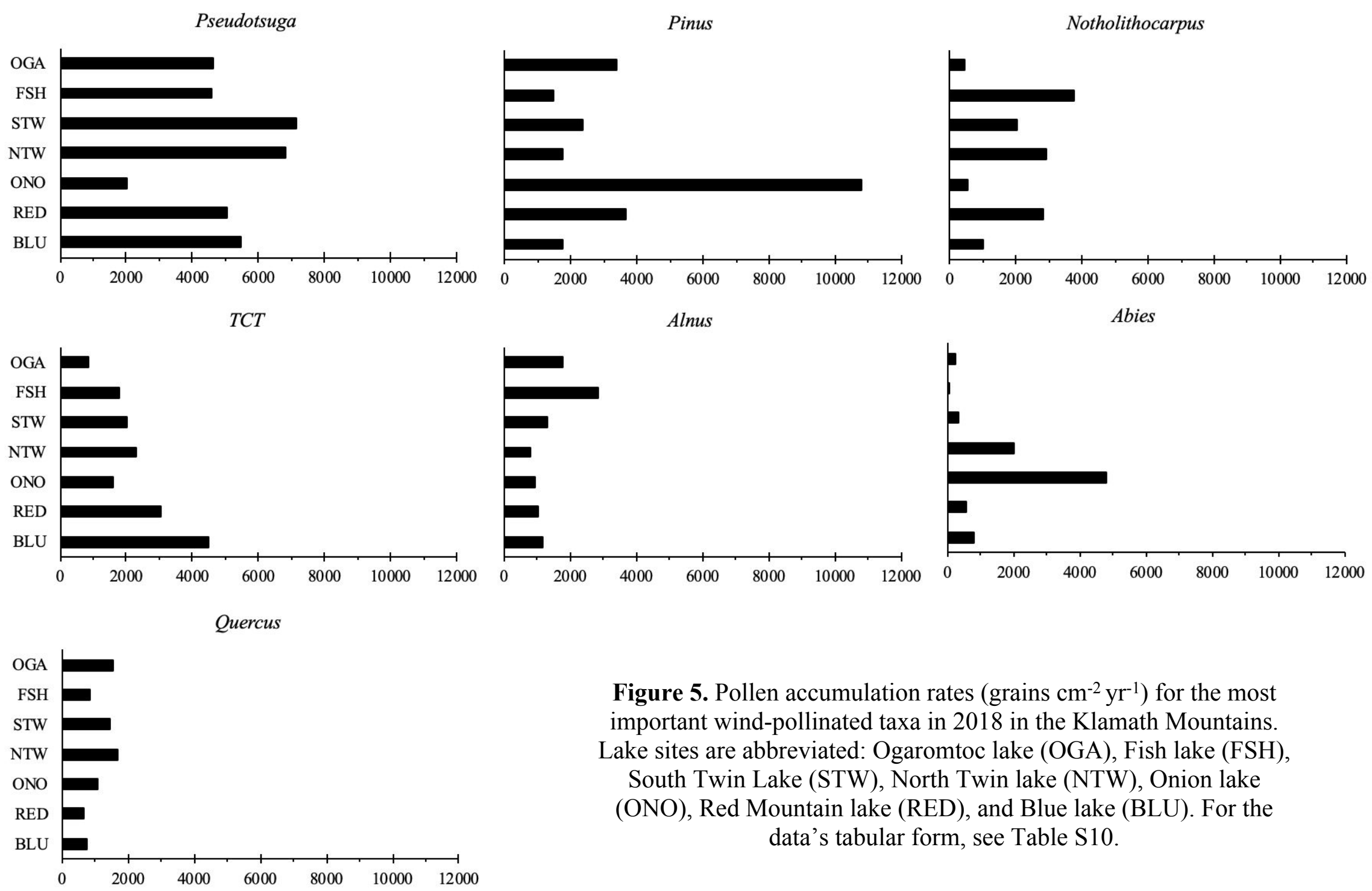

Figure 5. Pollen accumulation rates (grains $\mathrm{cm}^{-2} \mathrm{yr}^{-1}$ ) for the most important wind-pollinated taxa in 2018 in the Klamath Mountains. Lake sites are abbreviated: Ogaromtoc lake (OGA), Fish lake (FSH), South Twin Lake (STW), North Twin lake (NTW), Onion lake (ONO), Red Mountain lake (RED), and Blue lake (BLU). For the data's tabular form, see Table S10. 


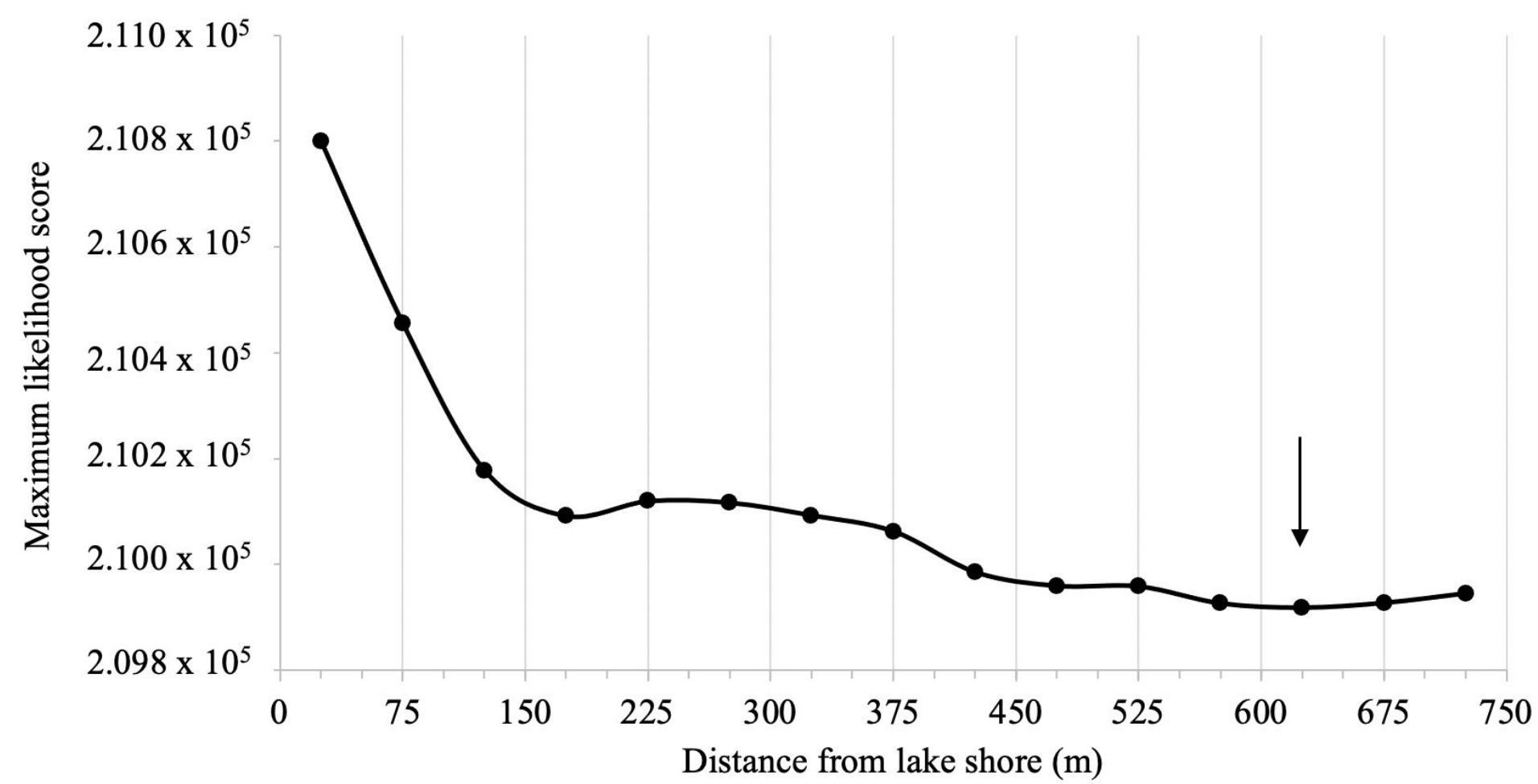

Figure 6. PolERV model 3 results of maximum likelihood scores compared to distance $(\mathrm{m})$. Arrow indicates the aRSAP value $(625 \mathrm{~m})$. 

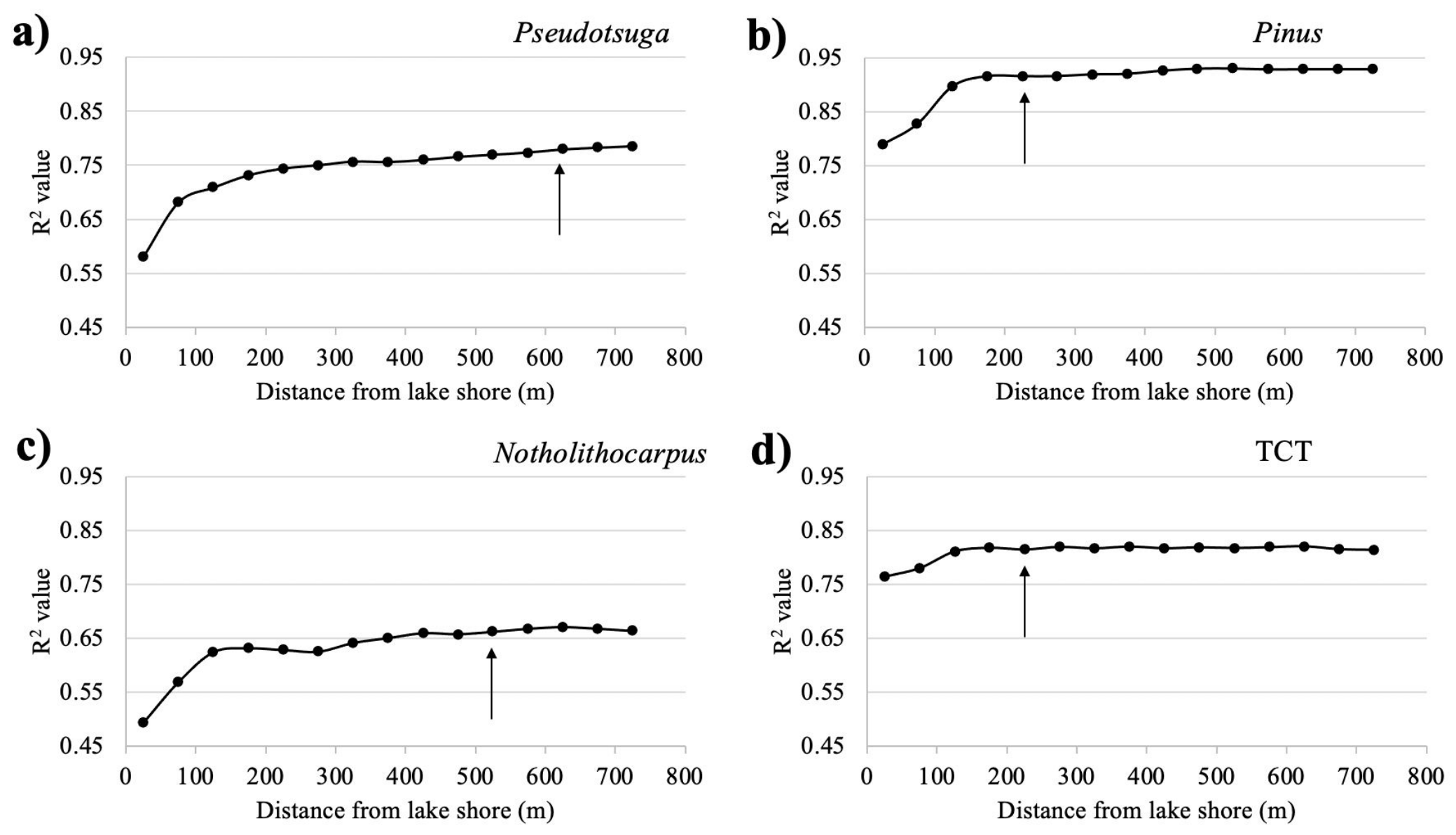

Figure 7. $\mathrm{R}^{2}$ for regressions between $\mathrm{AGL}_{\mathrm{dw}}$ and $\mathrm{PAR}$ at increasing distance from the lake shore to the furthest vegetation survey site. tRSAP is shown by the arrow: a) Pseudotsuga $(625 \mathrm{~m})$, b) Pinus (225m), c) Notholithocarpus (525m), and d) TCT (225m). 


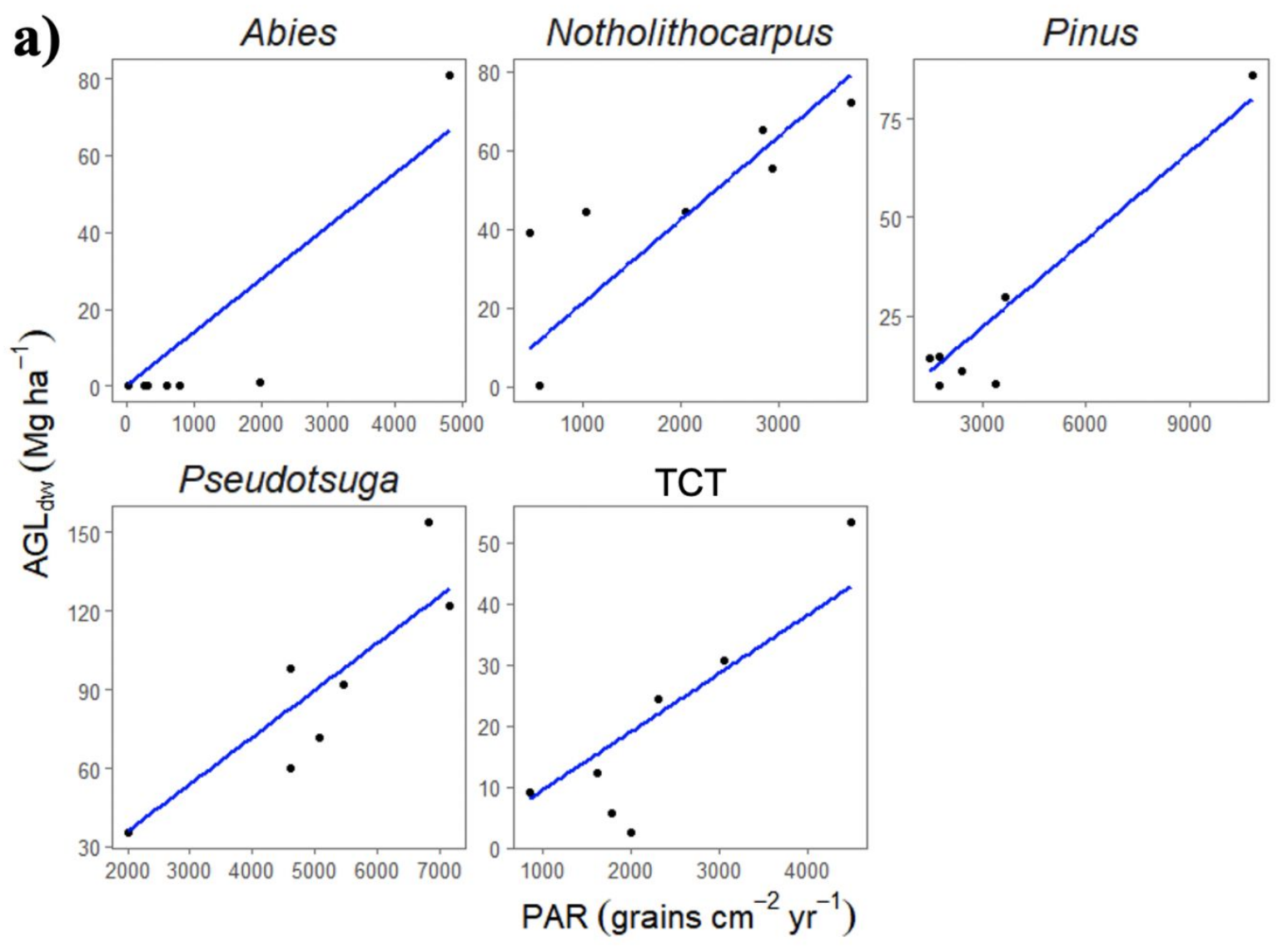

Figure 8a. The relationship between distance-weighted aboveground live biomass ( $\left.\mathrm{AGL}_{\mathrm{DW}}\right)$ and pollen accumulation rate (PAR) for five of the pollen taxa present at the seven lake sites in the Klamath Mountains. Lines represent linear regressions forced through the origin. The relevant source area of pollen (aRSAP) was defined as a circle with a radius of $625 \mathrm{~m}$ from the centroid of the lake. Note that the scales change for each pollen taxa. For summaries of the linear models, see Table S11. (Note: Although biomass "predicts" pollen accumulation rates in a functional sense, our aim is to eventually apply calibrated transfer functions to predict biomass in the past; thus, we fitted regression lines with PAR values as the independent variable.) 

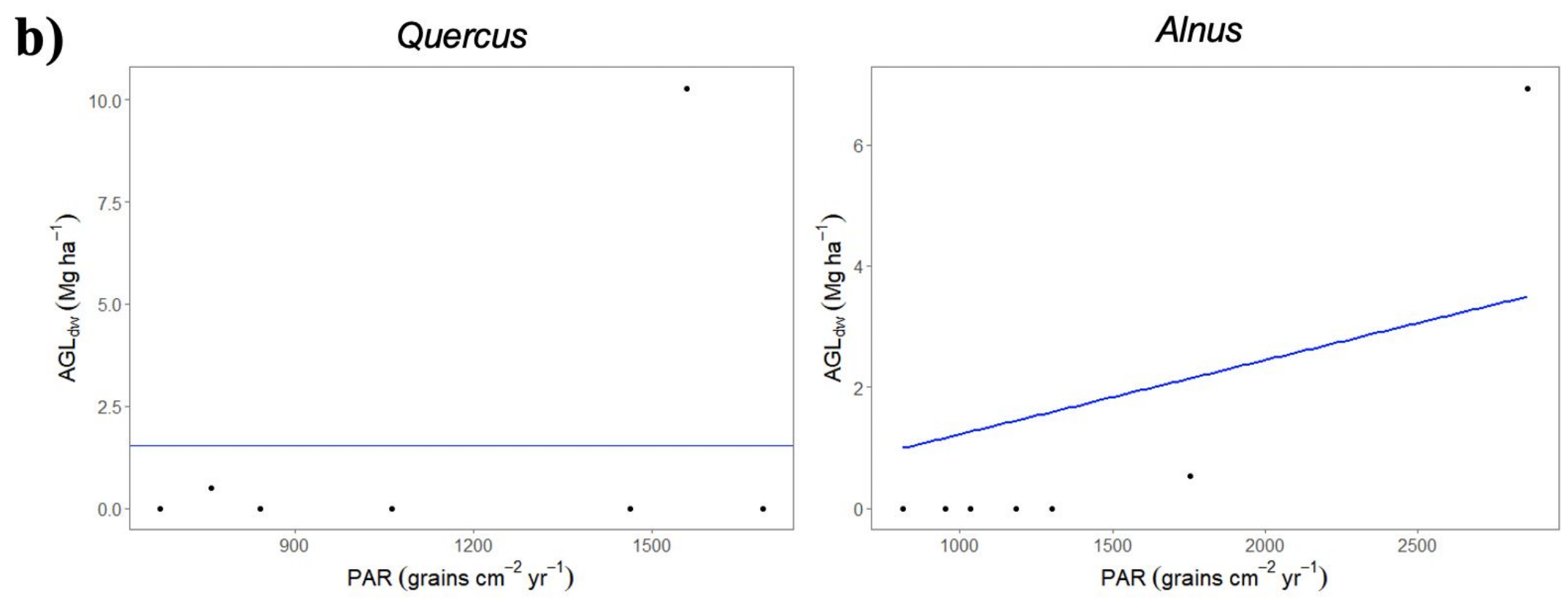

Figure 8b. The relationship between distance-weighted aboveground live biomass $\left(\mathrm{AGL}_{\mathrm{dw}}\right)$ and pollen accumulation rate (PAR) for Quercus and Alnus at the seven lake sites in the Klamath Mountains. The line represents the intercept of the null model. The relevant source area of pollen was defined as a circle with a radius of $625 \mathrm{~m}$ from the centroid of the lake. For details on the linear model, see Table S11. 
Table 1. Lake site characteristics and overstory vegetation at each site.

\begin{tabular}{|c|c|c|c|c|c|}
\hline $\begin{array}{l}\text { Lake site } \\
\text { and code }\end{array}$ & $\begin{array}{l}\text { Lat and long } \\
\text { (dec. degrees) }\end{array}$ & $\begin{array}{l}\text { Elevation } \\
\quad(\mathrm{m})\end{array}$ & $\begin{array}{c}\text { Depth at } \\
\text { deepest } \\
\text { point/sample } \\
\text { location }(\mathbf{m})\end{array}$ & $\begin{array}{c}\text { Surface } \\
\text { area (ha) }\end{array}$ & $\begin{array}{c}\text { Mature overstory } \\
\text { vegetation }\end{array}$ \\
\hline $\begin{array}{c}\text { Blue } \\
\text { (BLU) }\end{array}$ & $-123.69,41.24$ & 822 & 4.6 & 1.4 & $\begin{array}{c}\text { C. lawsoniana, } P \text {. menziesii, C. chrysaphylla, } N \text {. } \\
\text { densiflora, A. menziesii, A. rhombifolia, } P . \\
\text { lambertiana, T. brevifolia }\end{array}$ \\
\hline $\begin{array}{l}\text { Fish } \\
(\mathrm{FSH})\end{array}$ & $-123.68,41.26$ & 541 & 13 & 9.6 & $\begin{array}{c}\text { C. lawsoniana, P. menziesii, P. lambertiana, } \\
\text { N. densiflora, A. menziesii, A. rhombifolia, } C . \\
\text { chrysaphylla }\end{array}$ \\
\hline $\begin{array}{l}\text { North Twin } \\
\text { (NTW) }\end{array}$ & $-123.67,41.32$ & 1142 & 0.5 & 3.4 & P. menziesii, $P$. lambertiana, C. lawsoniana, $C$. \\
\hline $\begin{array}{l}\text { South Twin } \\
\text { (STW) }\end{array}$ & $-123.67,41.31$ & 1137 & 1.2 & 3.5 & $\begin{array}{l}\text { chrysaphylla, P. jeffreyi, T. heterophylla, } C \text {. } \\
\text { decurrens, } N . \text { densiflora, A. menziesii }\end{array}$ \\
\hline $\begin{array}{l}\text { Onion } \\
(\mathrm{ONO})\end{array}$ & $-123.75,41.38$ & 1356 & 1.5 & 0.66 & $\begin{array}{c}\text { P. ponderosa, P. menziesii, A. magnifica, } C \text {. } \\
\text { decurrens, A. concour, P. lambertiana, T. brevifolia }\end{array}$ \\
\hline $\begin{array}{l}\text { Ogaromtoc } \\
\text { (OGA) }\end{array}$ & $-123.54,41.49$ & 600 & 6.3 & 1.74 & $\begin{array}{c}\text { P. menziesii, N. densiflora, P. lambertiana, } A \text {. } \\
\text { macrophylla, A. rhombifolia, A. menziesii, } U \text {. } \\
\text { californica, C. decurrens, Q. kelloggii, Q. garryana }\end{array}$ \\
\hline $\begin{array}{l}\text { Red Mountain } \\
\text { (RED) }\end{array}$ & $-123.69,41.25$ & 768 & 1.6 & 1.2 & $\begin{array}{c}\text { C. lawsoniana, P. menziesii, P. lambertiana, } \\
\text { N.densiflora, A. menziesii, A. rhombifolia, } C . \\
\text { chrysaphylla }\end{array}$ \\
\hline
\end{tabular}


Table 2. Definitions of RSAP, aRSAP, and tRSAP.

Term

Definitional basis and relevant literature

Originally described by Sugita (1994) as the "smallest area within which reliable estimates of parameter values and asymptotic $\mathrm{r}^{2}$ or likelihood function scores can be obtained." The definition was refined as the "distance from a pollen deposition point beyond which the relationship between vegetation composition RSAP and pollen assemblage does not improve" (Bunting et al. 2004, with Sugita). Estimates are derived for the overall assemblage from extended R-value analysis (Parsons and Prentice 1981) through inspection of the likelihood function score plot. RSAP varies depending on which taxa and which sites are included in the analysis, thus is dependent on the assemblage chosen for analysis.

aRSAP

Identical to the standard RSAP, but with the addition of an "a" to denote that it is an assemblage-specific metric, in contrast to the tRSAP.

The RSAP concept can be extended to single taxa where pollen taxa are measured independently (e.g., PAR values rather than percentage values). In tRSAP this situation, we define a taxon-specific Relevant Source Area of Pollen, the tRSAP, as the distance beyond which the correlation between PAR (Y) and distance-weighted plant abundance $(\psi)$ summed to that distance for a single taxon does not improve (Jackson 1990). 
Table 3. A comparison of observed to predicted distance-weighted aboveground live biomass $\left(\mathrm{AGL}_{\mathrm{dw}}\right)$ for each lake site using the assemblage-level relevant source area pollen (aRSAP) estimates. Predicted $\mathrm{AGL}_{\mathrm{dw}}$ is the mean from 10,000 resampling iterations; Standard Error is the standard deviation of the 10,000 samples; COV is the coefficient of variation (Standard Error/Predicted $\mathrm{AGL}_{\mathrm{dw}}$ ); Bias is the percent difference between predicted and observed $\mathrm{AGL}_{\mathrm{DW}}$.

\begin{tabular}{lccccc}
\hline Lake & $\begin{array}{c}\text { Observed AGL } \\
\left(\mathrm{Mg} \mathrm{ha}^{-1}\right)\end{array}$ & $\begin{array}{c}\text { Predicted AGL } \\
\left(\mathrm{Mg} \mathrm{ha}^{-1}\right)\end{array}$ & $\begin{array}{c}\text { Standard Error } \\
\left(\mathrm{Mg} \mathrm{ha}^{-1}\right)\end{array}$ & $\begin{array}{c}\text { COV } \\
(\%)\end{array}$ & $\begin{array}{c}\text { Bias } \\
(\%)\end{array}$ \\
\hline Blue & 205 & 189 & 31.5 & 17 & -7.8 \\
Fish & 197 & 195 & 31.8 & 16 & -1.1 \\
North Twin & 242 & 251 & 32.0 & 13 & 3.7 \\
Ogaromtoc & 127 & 134 & 31.6 & 24 & 5.7 \\
Onion & 215 & 212 & 32.1 & 15 & -1.1 \\
Red Mountain & 197 & 218 & 31.4 & 14 & 10.5 \\
South Twin & 180 & 217 & 31.6 & 15 & 20.5 \\
\hline
\end{tabular}

Table 4. A comparison of observed to predicted distance-weighted aboveground live biomass $\left(\mathrm{AGL}_{\mathrm{dw}}\right)$ for each lake site using taxon-specific source area pollen estimates (tRSAP). Predicted $\mathrm{AGL}_{\mathrm{dw}}$ is the mean from 10,000 resampling iterations; Standard Error is the standard deviation of the 10,000 samples; COV is the coefficient of variation (Standard Error/Predicted $\mathrm{AGL}_{\mathrm{DW}}$ ); Bias is the percent difference between predicted and observed $A G L_{d w}$.

\begin{tabular}{lccccc}
\hline Lake & $\begin{array}{c}\text { Observed AGL } \\
\left(\mathrm{Mg} \mathrm{ha}^{-1}\right)\end{array}$ & $\begin{array}{c}\text { Predicted AGL } \\
\left(\mathrm{Mg} \mathrm{ha}^{-1}\right)\end{array}$ & $\begin{array}{c}\text { Standard Error } \\
\left(\mathrm{Mg} \mathrm{ha}^{-1}\right)\end{array}$ & $\begin{array}{c}\text { COV } \\
(\%)\end{array}$ & $\begin{array}{c}\text { Bias } \\
(\%)\end{array}$ \\
\hline Blue & 196 & 189 & 31.5 & 17 & -3.7 \\
Fish & 185 & 195 & 31.8 & 16 & 5.2 \\
North Twin & 239 & 251 & 32.0 & 13 & 4.9 \\
Ogaromtoc & 121 & 134 & 31.6 & 24 & 10.6 \\
Onion & 193 & 212 & 32.1 & 15 & 10.3 \\
Red & 184 & 218 & 31.4 & 14 & 18.4 \\
South Twin & 173 & 217 & 31.6 & 15 & 24.9 \\
\hline
\end{tabular}




\section{Supplemental Information}

Title: Linking modern pollen accumulation rates to biomass: Quantitative vegetation reconstruction in the western Klamath Mountains

Authors: Clarke A. Knight, Mark Baskaran, M. Jane Bunting, Marie Champagne, Matthew D. Potts, David Wahl, James Wanket, John J. Battles 


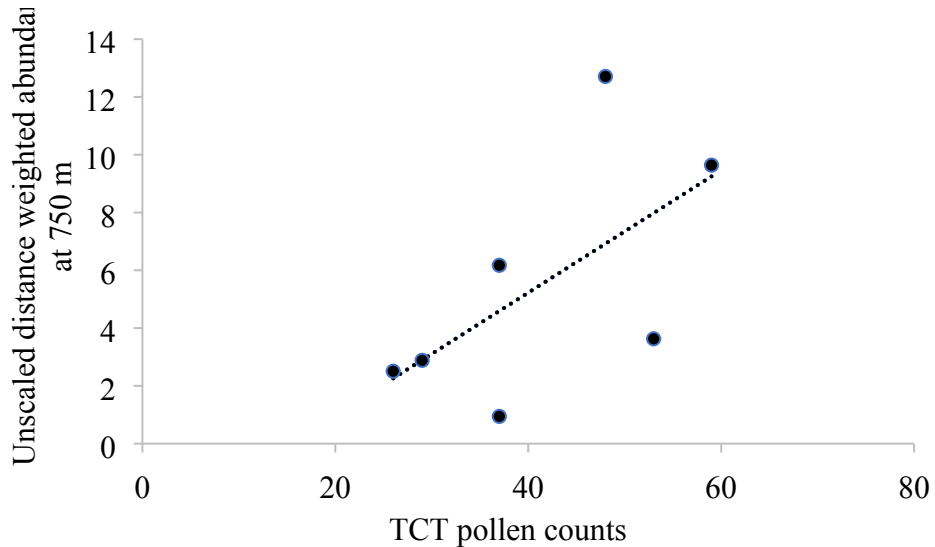

Figure S1. TCT pollen counts corrected to the same base sum plotted against unscaled distance weighted plant abundance at $750 \mathrm{~m}$ to determine the reference taxon for the PolERV model. 


\section{Sediment dating and age-depth model}

We used lead-210 $\left({ }^{210} \mathrm{~Pb} ; 22.3 \mathrm{yr}\right.$ half-life $)$ to assign ages to sediment deposited in the last 150 years. Surface bulk sediments from $0 \mathrm{~cm}$ to a maximum of $45 \mathrm{~cm}$ were taken from each core and dried to $105^{\circ} \mathrm{C}$ (see Tables $\left.\mathrm{S} 1-\mathrm{S} 7\right) .{ }^{210} \mathrm{~Pb}$ activity was determined by alpha spectrometry, via ${ }^{210} \mathrm{Po}$. An aliquot of 0.2 to $1.0 \mathrm{~g}$ of dried and pulverized sample was digested using concentrated $\mathrm{HF}, \mathrm{HNO}_{3}$, and $\mathrm{HCl}$ and a known amount of ${ }^{209} \mathrm{Po}$ spike in an oven at $90^{\circ} \mathrm{C}$ for $\sim 24$ hours. The digested solution was dried, and the residue was mixed with $1 \mathrm{M} \mathrm{HCl} \mathrm{until} \mathrm{the} \mathrm{pH}$ was $\sim 2$. Autoplating of Po was cold-plated onto an Ag disk for 24 hours at room temperature (Jweda and Baskaran 2011). The plated disk was assayed for Po using Octete PC ORTEC alpha spectrometer. The reagent blanks were run simultaneously with each batch of eight samples and were subtracted. Certified reference materials were periodically run. For the determination of parent-supported (i.e., background) ${ }^{210} \mathrm{~Pb}$, several samples were run for the activity of ${ }^{226} \mathrm{Ra}$ (using 352 and $609 \mathrm{keV}$ ) along with ${ }^{137} \mathrm{Cs}(661.6 \mathrm{keV})$ by Ge-well detector (Baskaran et al. 2015). Small sample sizes prevented reliable ${ }^{137} \mathrm{Cs}$ from being obtained.

We used the Bayesian-based Plum software to develop age models from excess (unsupported) ${ }^{210} \mathrm{~Pb}$ data (Aquino-López et al. 2018). The Plum model is related to the constant rate of supply (CRS) method (Appleby and Oldfield 1978) and retains two of the basic assumptions of CRS: the rate of supply of ${ }^{210} \mathrm{~Pb}$ is constant and there is no vertical mixing of radionuclides. Testing these assumptions requires independent validation using another marker, which is outside of this paper's scope. The Plum model is formulated within a robust statistical framework to quantify uncertainty (Aquino-López et al. 2018). Plum uses a self-adjusting Markov Chain Monte Carlo (MCMC) algorithm called the t-walk (Christen and Fox 2010). Plum uses millions of MCMC iterations to model the accumulation of sediment, using a gamma 
autoregressive semiparametric age-depth function (Blaauw and Christen 2011). This algorithm results in a probability envelope around the mean age model. The envelope allows the precision at any depth to be estimated explicitly. Plum makes use of prior information to determine the datable horizon, which is affected by two factors: the precision of methodology (alpha versus gamma counting) and the initial amount of excess lead. In Plum, the chronology limit is determined by the rate of supply of ${ }^{210} \mathrm{~Pb}$ to the site and the equipment error, usually $\sim 3 \mathrm{~Bq} / \mathrm{kg}$ for a sample size of $1 \mathrm{~g}$ by alpha spectrometry for research laboratories. Supported ${ }^{210} \mathrm{~Pb}$ activities were determined from the direct measurements of ${ }^{226}$ Ra by gamma-ray spectrometry. 
Figure S2. The age-to-depth results of the Plum model for Fish, Ogaromtoc, Onion, North Twin, Red Mountain, and South Twin Lakes. The grey lines are simulation from Plum and the dashed red lines represent the mean age and the $95 \%$ interval. The small panels at the top show the prior (green) and posterior (grey) distributions for (a) the memory $(\omega)$, (b) the sedimentation rate $(\alpha)$, (c) the supported ${ }^{210} \mathrm{~Pb}\left(\mathrm{PS}^{\mathrm{S}}\right)$, which is the background level of ${ }^{210} \mathrm{~Pb}$ already present in the sediment, and (d) and the supply of ${ }^{210} \mathrm{~Pb}(\Phi)$.

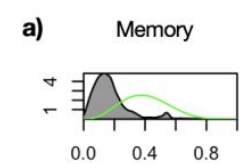

b) Sedimentation rate
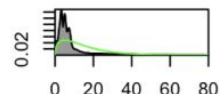

$\mathrm{cm} / \mathrm{yr}$
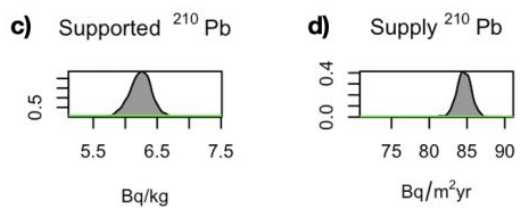

Fish Lake

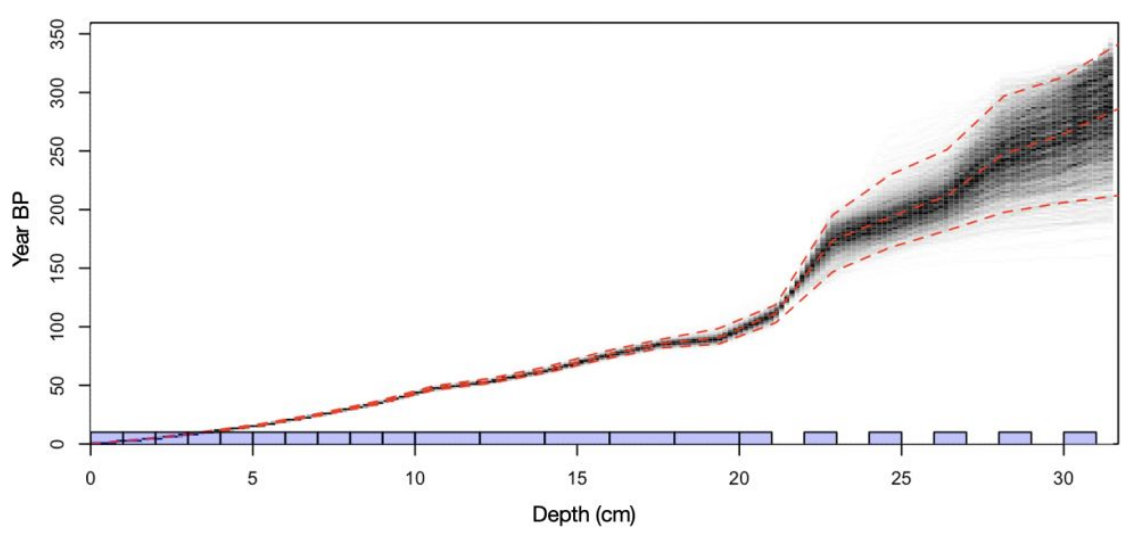




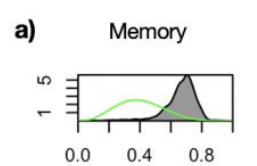

b) Sedimentation rate

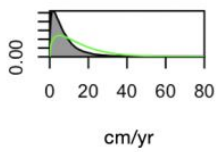

c) Supported ${ }^{210} \mathrm{~Pb}$

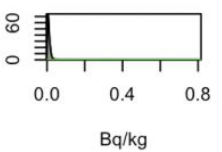

d) Supply ${ }^{210} \mathrm{~Pb}$

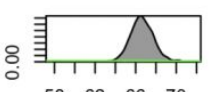

$\begin{array}{llll}58 & 62 & 66 & 70\end{array}$ $\mathrm{Bq} / \mathrm{m}^{2} \mathrm{yr}$

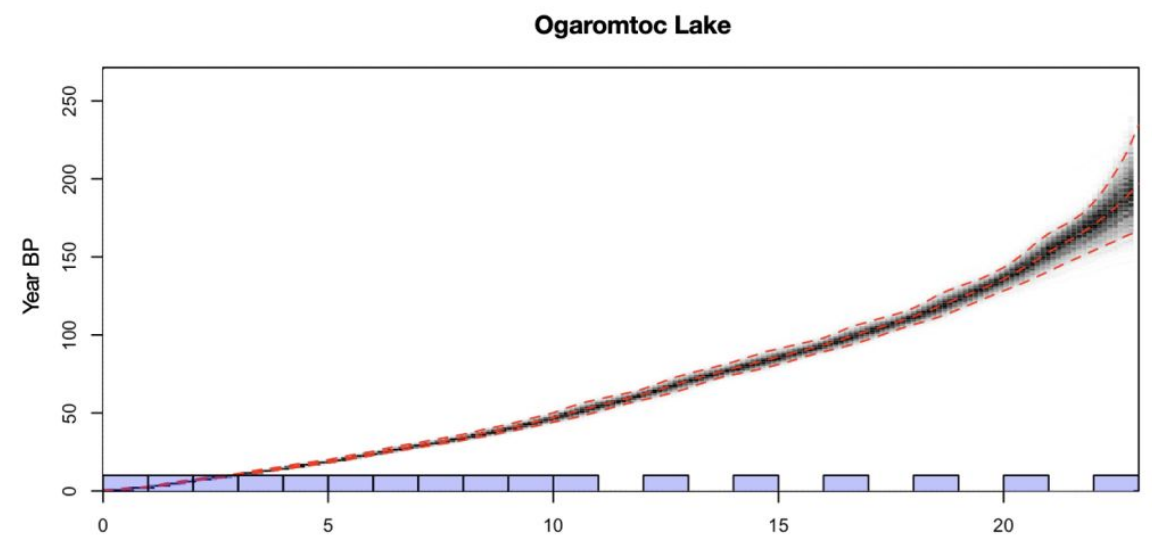

b) Sedimentation rate

c) Supported ${ }^{210} \mathrm{~Pb}$

d) Supply ${ }^{210} \mathrm{~Pb}$
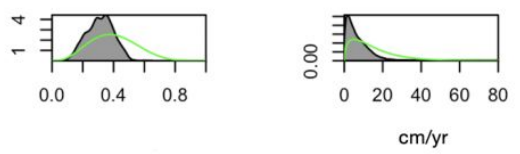

$\circ \underbrace{}_{1,1,1,1}$

$\begin{array}{llll}0.2 & 0.6 & 1.0 & 1.4\end{array}$

$\mathrm{Bq} / \mathrm{kg}$
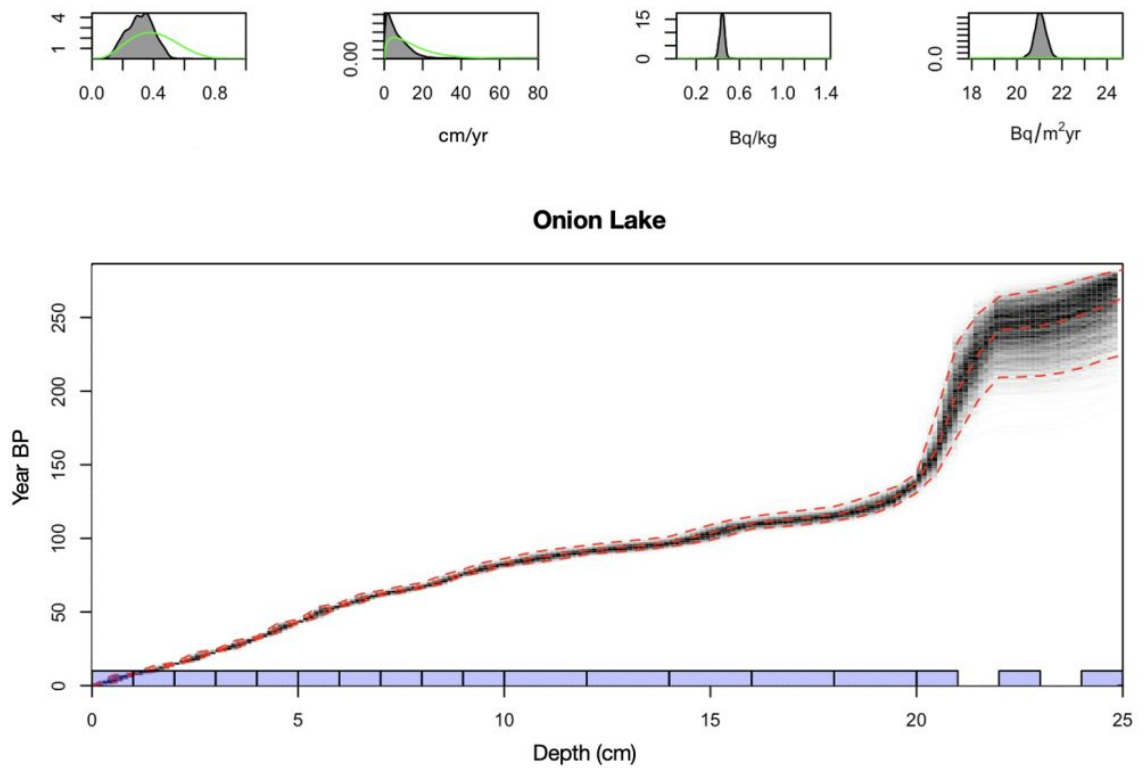

6 


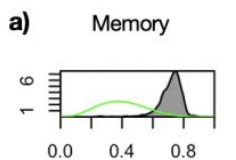

b) Sedimentation rate

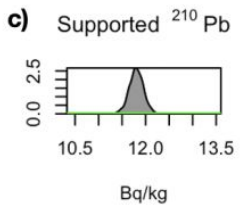

d) Supply ${ }^{210} \mathrm{~Pb}$
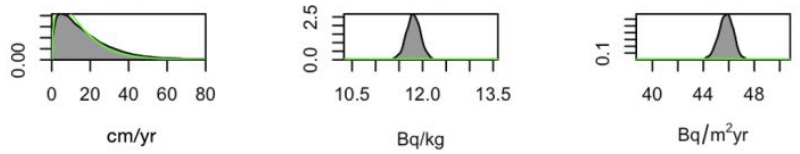

North Twin Lake

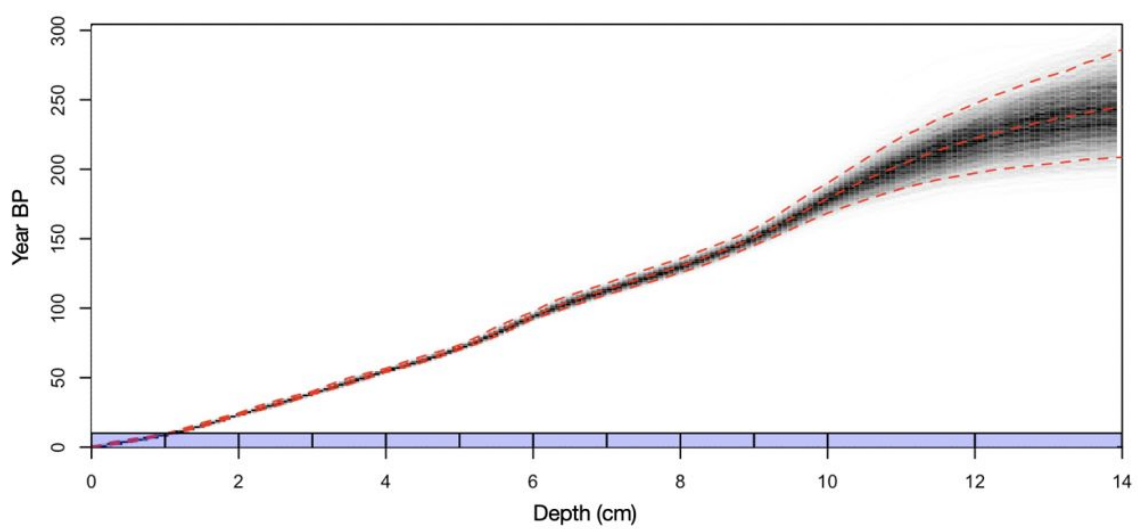

a) Memory

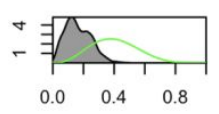

b) Sedimentation rate

c) Supported ${ }^{210} \mathrm{~Pb}$

d) Supply ${ }^{210} \mathrm{~Pb}$
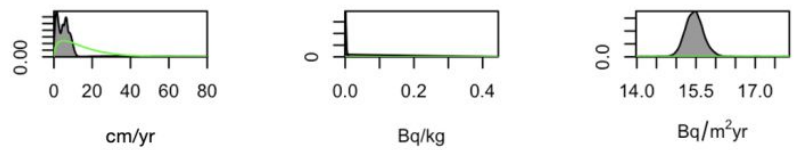

Red Mountain Lake

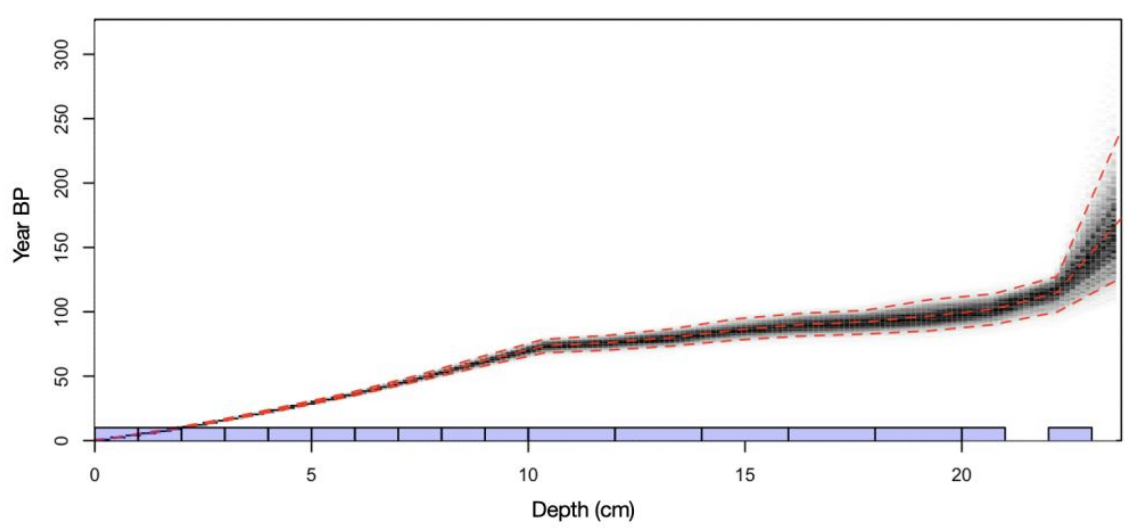

7 

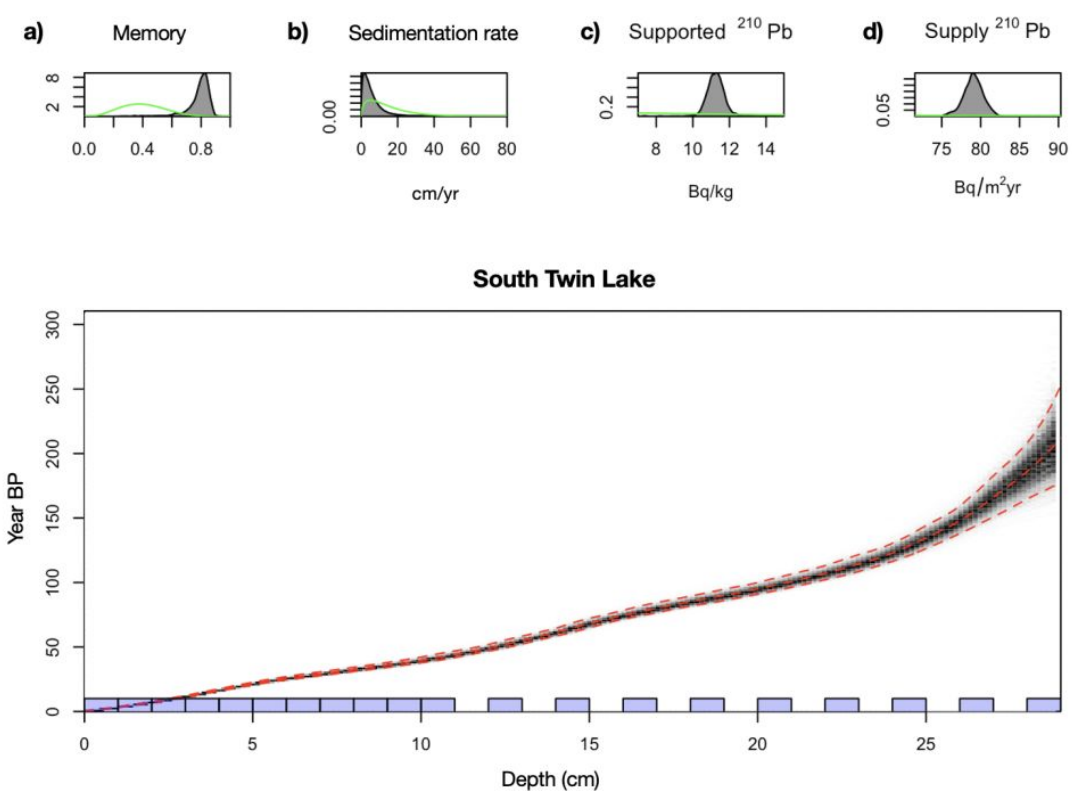


\section{Lithology}

Cores were split lengthwise and measured for magnetic susceptibility at every half centimeter using a calibrated MS2E surface scanning point sensor (MS Bartsoft). Changes in lithology were described and documented. The water content and dry bulk density were determined for each core in 1 or $2 \mathrm{~cm}$ intervals (Tables S14-S20), matching the sampling pattern for radioisotopic analysis (Table S1-S7).

Cores were composed of unlaminated gyttja. Occasional diatomaceous lenses $(<1 \mathrm{~cm}$ thick) were present in Blue and Ogaromtoc lakes. For the Onion lake core, pine needles were visible in the top $3 \mathrm{~cm}$, but needles were not seen in the other cores. Magnetic susceptibility was near zero for Blue, North Twin, Red Mountain, and South Twin lakes, and although magnetic susceptibility in Ogaromtoc lake was also generally low, Ogaromtoc had two distinct peaks (Fig. S3). Fish and Onion lakes showed higher overall magnetic susceptibility than the other lakes, as well as more variation across depths (Fig. S4). Peaks in magnetic susceptibility generally corresponded to increases in dry bulk density $\left(\mathrm{g} \mathrm{cm}^{-3}\right)$ for Ogaromtoc, Fish, and Onion lakes (Tables S19, S17, S16, respectively). For example, two peaks at $14-15 \mathrm{~cm}$ and $22-23 \mathrm{~cm}$ in Ogaromtoc matched the depths where dry bulk density tripled and doubled, respectively. Ogaromtoc also had two light blue clay bands at $14-15 \mathrm{~cm}$ and $22-23 \mathrm{~cm}$. Other cores did not contain clear stratigraphic markers. 

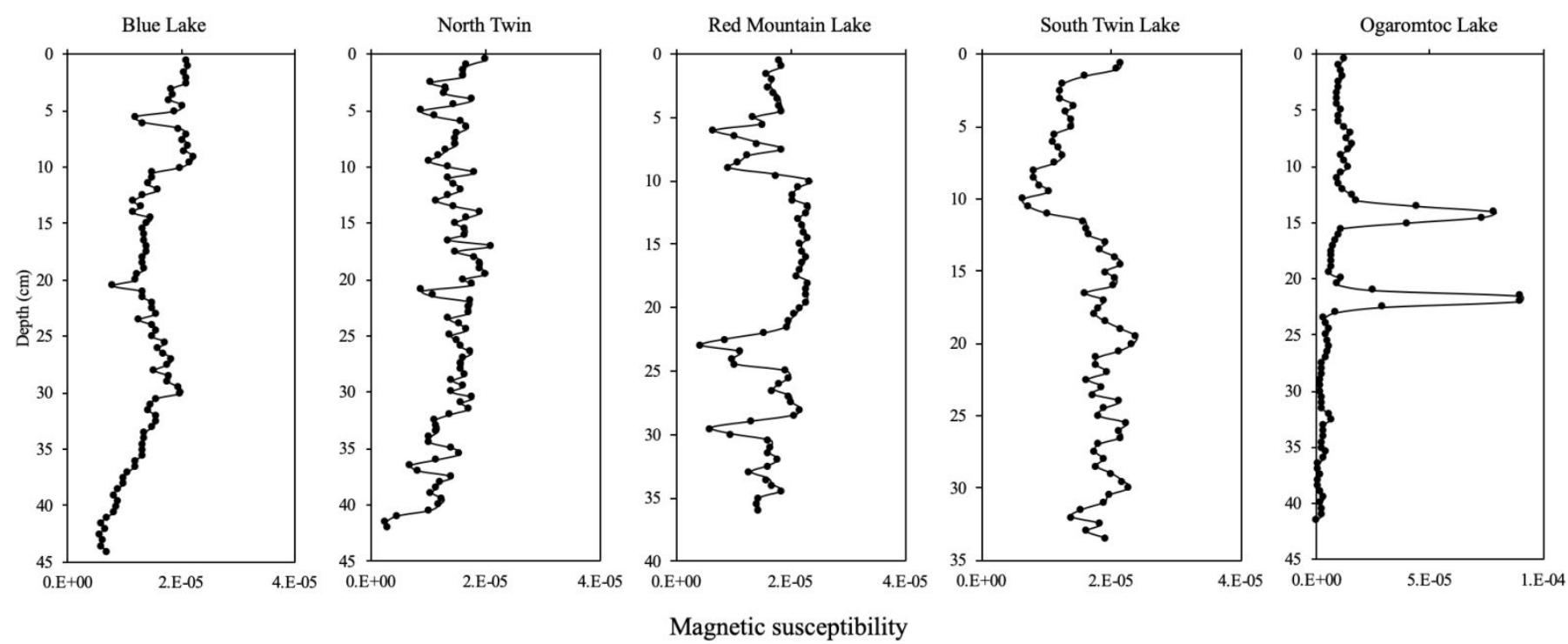

Figure S3. Magnetic susceptibility for the five study sites. The magnetic susceptibility was near zero with some variability for five lakes (note different X-axis for Ogaromtoc) - Blue, North Twin, Red Mountain, South Twin and Ogaromtoc Lakes. 

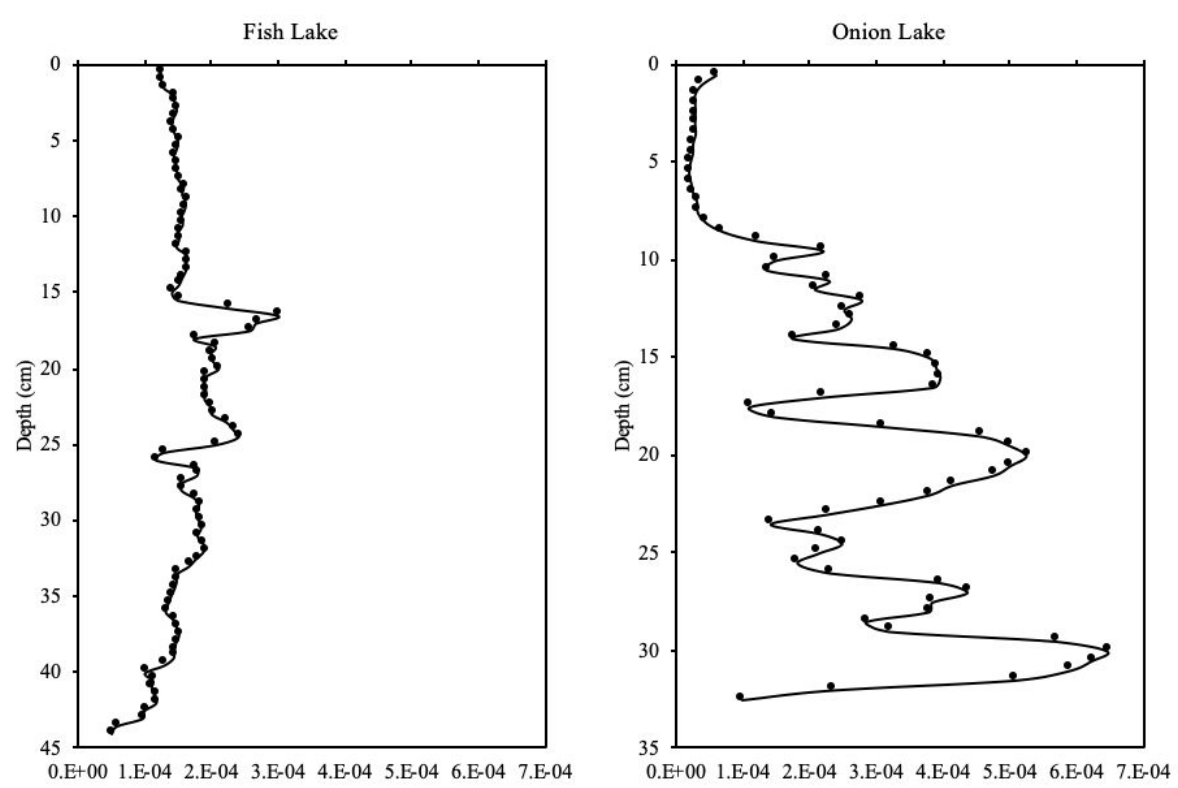

Figure S4. Magnetic susceptibility for the two study sites. Fish and Onion lakes (same $\mathrm{X}$-axis) displayed higher overall magnetic susceptibility than the other five lake sites. 
Table S1. ${ }^{210} \mathrm{~Pb}$ dates used to create the Blue Lake age model.

\begin{tabular}{|c|c|c|c|c|c|c|c|}
\hline Sample & $\begin{array}{l}\text { Depth } \\
\text { (cm) }\end{array}$ & Age (yr) & $\begin{array}{c}\text { Uncertainty } \\
\text { (yr) }\end{array}$ & Sample & $\begin{array}{c}\text { Depth } \\
\text { (cm) }\end{array}$ & Age (yr) & $\begin{array}{c}\text { Uncertainty } \\
\text { (yr) }\end{array}$ \\
\hline $210 \mathrm{~Pb} \_1$ & 0.5 & 3 & 0.3 & $210 \mathrm{~Pb} \_12$ & 13.0 & 38 & 2 \\
\hline $210 \mathrm{~Pb} \_2$ & 1.5 & 6 & 0.5 & $210 \mathrm{~Pb} \_13$ & 15.0 & 45 & 3 \\
\hline $210 \mathrm{~Pb} \_3$ & 2.5 & 9 & 0.6 & $210 \mathrm{~Pb} \_14$ & 17.0 & 50 & 3 \\
\hline $210 \mathrm{~Pb} \_4$ & 3.5 & 12 & 0.7 & $210 \mathrm{~Pb} \_15$ & 19.0 & 57 & 4 \\
\hline $210 \mathrm{~Pb} \_5$ & 4.5 & 15 & 0.9 & $210 \mathrm{~Pb} \_16$ & 20.5 & 69 & 5 \\
\hline $210 \mathrm{~Pb} 66$ & 5.5 & 19 & 1 & $210 \mathrm{~Pb} \_17$ & 22.5 & 87 & 9 \\
\hline $210 \mathrm{~Pb} \_7$ & 6.5 & 23 & 1 & $210 \mathrm{~Pb} \_18$ & 24.5 & 103 & 13 \\
\hline $210 \mathrm{~Pb} \_8$ & 7.5 & 27 & 2 & $210 \mathrm{~Pb} \_19$ & 26.5 & 125 & 21 \\
\hline 210Pb_9 & 8.5 & 31 & 2 & $210 \mathrm{~Pb} \_20$ & 28.5 & 146 & 27 \\
\hline $210 \mathrm{~Pb} \_10$ & 9.5 & 34 & 2 & $210 \mathrm{~Pb} \_21$ & 30.5 & 175 & 57 \\
\hline $210 \mathrm{~Pb} \_11$ & 11.0 & 37 & 2 & & & & \\
\hline
\end{tabular}

Table S2. ${ }^{210} \mathrm{~Pb}$ dates used to create the Fish Lake age model.

\begin{tabular}{|c|c|c|c|c|c|c|c|}
\hline Sample & $\begin{array}{c}\text { Depth } \\
\text { (cm) }\end{array}$ & Age (yr) & $\begin{array}{c}\text { Uncertainty } \\
\text { (yr) }\end{array}$ & Sample & $\begin{array}{l}\text { Depth } \\
\text { (cm) }\end{array}$ & Age (yr) & $\begin{array}{c}\text { Uncertainty } \\
\text { (yr) }\end{array}$ \\
\hline 210Pb_1 & 0.5 & 2 & 0.2 & $210 \mathrm{~Pb} \_12$ & 12.5 & 58 & 2 \\
\hline $210 \mathrm{~Pb} \_2$ & 1.5 & 5 & 0.4 & $210 \mathrm{~Pb} \_13$ & 14.5 & 70 & 3 \\
\hline $210 \mathrm{~Pb} \_3$ & 2.5 & 8 & 0.5 & $210 \mathrm{~Pb} \_14$ & 16.5 & 82 & 4 \\
\hline $210 \mathrm{~Pb} \_4$ & 3.5 & 12 & 0.6 & $210 \mathrm{~Pb} \_15$ & 18.5 & 90 & 6 \\
\hline $210 \mathrm{~Pb} \_5$ & 4.5 & 15 & 0.7 & $210 \mathrm{~Pb} \_16$ & 20.5 & 110 & 7 \\
\hline 210Pb_6 & 5.5 & 20 & 0.8 & $210 \mathrm{~Pb} \_17$ & 22.5 & 175 & 25 \\
\hline $210 \mathrm{~Pb} \_7$ & 6.5 & 25 & 1 & $210 \mathrm{~Pb} \_18$ & 24.5 & 197 & 32 \\
\hline $210 \mathrm{~Pb} \_8$ & 7.5 & 30 & 1 & 210Pb_19 & 26.5 & 224 & 40 \\
\hline 210Pb_9 & 8.5 & 36 & 1 & $210 \mathrm{~Pb} \_20$ & 28.5 & 244 & 51 \\
\hline $210 \mathrm{~Pb} \_10$ & 9.5 & 44 & 2 & $210 \mathrm{~Pb} \_21$ & 30.5 & 277 & 60 \\
\hline $210 \mathrm{~Pb} \_11$ & 10.5 & 49 & 2 & & & & \\
\hline
\end{tabular}


Table S3. ${ }^{210} \mathrm{~Pb}$ dates used to create the Ogaromtoc Lake age model. An outlier point at $6.5 \mathrm{~cm}$ was excluded from the model.

\begin{tabular}{|c|c|c|c|c|c|c|c|}
\hline Sample & $\begin{array}{l}\text { Depth } \\
\text { (cm) }\end{array}$ & Age (yr) & $\begin{array}{c}\text { Uncertainty } \\
(y \mathbf{y r})\end{array}$ & Sample & $\begin{array}{l}\text { Depth } \\
\text { (cm) }\end{array}$ & Age (yr) & $\begin{array}{c}\text { Uncertainty } \\
\text { (yr) }\end{array}$ \\
\hline 210Pb_1 & 0.5 & 3 & 0.2 & 210Pb_9 & 9.5 & 47 & 3 \\
\hline 210Pb_2 & 1.5 & 7 & 0.4 & $210 \mathrm{~Pb} \_10$ & 10.5 & 55 & 4 \\
\hline $210 \mathrm{~Pb} 33$ & 2.5 & 11 & 0.6 & $210 \mathrm{~Pb} \_11$ & 12.5 & 71 & 5 \\
\hline 210Pb_4 & 3.5 & 15 & 0.8 & $210 \mathrm{~Pb} \_12$ & 14.5 & 86 & 5 \\
\hline 210Pb_5 & 4.5 & 19 & 1 & 210Pb_13 & 16.5 & 103 & 6 \\
\hline 210Pb_6 & 5.5 & 24 & 1 & 210Pb_14 & 18.5 & 124 & 7 \\
\hline $210 \mathrm{~Pb} \_7$ & 7.5 & 34 & 2 & $210 \mathrm{~Pb} \_15$ & 20.5 & 153 & 12 \\
\hline $210 \mathrm{~Pb} \_8$ & 8.5 & 40 & 2 & $210 \mathrm{~Pb} \_16$ & 22.5 & 197 & 34 \\
\hline
\end{tabular}

Table S4. ${ }^{210} \mathrm{~Pb}$ dates used to create the Onion Lake age model.

\begin{tabular}{|c|c|c|c|c|c|c|c|}
\hline Sample & $\begin{array}{l}\text { Depth } \\
\text { (cm) }\end{array}$ & Age (yr) & $\begin{array}{c}\text { Uncertainty } \\
(\mathbf{y r})\end{array}$ & Sample & $\begin{array}{l}\text { Depth } \\
\text { (cm) }\end{array}$ & Age (yr) & $\begin{array}{c}\text { Uncertainty } \\
\text { (yr) }\end{array}$ \\
\hline 210Pb_1 & 0.5 & 8 & 0.6 & $210 \mathrm{~Pb} \_10$ & 9.5 & 83 & 3 \\
\hline $210 \mathrm{~Pb} 2$ & 1.5 & 15 & 0.7 & $210 \mathrm{~Pb} \_11$ & 11.0 & 88 & 4 \\
\hline $210 \mathrm{~Pb} 33$ & 2.5 & 24 & 0.9 & $210 \mathrm{~Pb} \_12$ & 13.0 & 94 & 4 \\
\hline $210 \mathrm{~Pb}-4$ & 3.5 & 32 & 1 & $210 \mathrm{~Pb} \_13$ & 15.0 & 104 & 5 \\
\hline 210Pb_5 & 4.5 & 44 & 1 & $210 \mathrm{~Pb} \_14$ & 17.0 & 113 & 5 \\
\hline 210Pb_6 & 5.5 & 54 & 2 & $210 \mathrm{~Pb} \_15$ & 19.0 & 123 & 7 \\
\hline $210 \mathrm{~Pb} \_7$ & 6.5 & 63 & 2 & $210 \mathrm{~Pb} \_16$ & 20.5 & 201 & 32 \\
\hline 210Pb_8 & 7.5 & 68 & 2 & $210 \mathrm{~Pb} \_17$ & 22.5 & 244 & 29 \\
\hline 210Pb_9 & 8.5 & 77 & 2 & $210 \mathrm{~Pb} \_18$ & 24.5 & 263 & 29 \\
\hline
\end{tabular}

Table S5. ${ }^{210} \mathrm{~Pb}$ dates used to create the North Twin Lake age model.

\begin{tabular}{cccccccc}
\hline Sample & $\begin{array}{c}\text { Depth } \\
(\mathbf{c m})\end{array}$ & Age (yr) & $\begin{array}{c}\text { Uncertainty } \\
(\mathbf{y r})\end{array}$ & Sample & $\begin{array}{c}\text { Depth } \\
(\mathbf{c m})\end{array}$ & Age (yr) & $\begin{array}{c}\text { Uncertainty } \\
(\mathbf{y r})\end{array}$ \\
\hline $210 \mathrm{~Pb} \_1$ & 0.5 & 2 & 0.4 & $210 \mathrm{~Pb} \_7$ & 6.5 & 112 & 4 \\
$210 \mathrm{~Pb} \_2$ & 1.5 & 24 & 0.8 & $210 \mathrm{~Pb} \_8$ & 7.5 & 128 & 5 \\
$210 \mathrm{~Pb} \_3$ & 2.5 & 39 & 1 & $210 \mathrm{~Pb} \_9$ & 8.5 & 147 & 6 \\
$210 \mathrm{~Pb} \_4$ & 3.5 & 55 & 1 & $210 \mathrm{~Pb} \_10$ & 9.5 & 173 & 10 \\
$210 \mathrm{~Pb} 55$ & 4.5 & 71 & 2 & $210 \mathrm{~Pb} \_11$ & 11.0 & 197 & 18 \\
$210 \mathrm{~Pb} \_6$ & 5.5 & 94 & 3 & $210 \mathrm{~Pb} \_12$ & 13.0 & 229 & 30
\end{tabular}


Table S6. ${ }^{210} \mathrm{~Pb}$ dates used to create the Red Mountain Lake age model.

\begin{tabular}{lccccccc}
\hline Sample & $\begin{array}{c}\text { Depth } \\
(\mathbf{c m})\end{array}$ & Age (yr) & $\begin{array}{c}\text { Uncertainty } \\
(\mathbf{y r})\end{array}$ & Sample & $\begin{array}{c}\text { Depth } \\
(\mathbf{c m})\end{array}$ & Age (yr) & $\begin{array}{c}\text { Uncertainty } \\
(\mathbf{y r})\end{array}$ \\
\hline $210 \mathrm{~Pb} \_1$ & 0.5 & 5 & 0.3 & $210 \mathrm{~Pb} \_10$ & 9.5 & 71 & 5 \\
$210 \mathrm{~Pb} 22$ & 1.5 & 10 & 0.2 & $210 \mathrm{~Pb} \_11$ & 11.0 & 75 & 6 \\
$210 \mathrm{~Pb} 33$ & 2.5 & 16 & 0.8 & $210 \mathrm{~Pb} \_12$ & 13.0 & 79 & 7 \\
$210 \mathrm{~Pb} 44$ & 3.5 & 23 & 1 & $210 \mathrm{~Pb} \_13$ & 15.0 & 87 & 8 \\
$210 \mathrm{~Pb} 55$ & 4.5 & 30 & 2 & $210 \mathrm{~Pb} \_14$ & 17.0 & 91 & 9 \\
$210 \mathrm{~Pb} 66$ & 5.5 & 37 & 2 & $210 \mathrm{~Pb} \_15$ & 19.0 & 96 & 12 \\
$210 \mathrm{~Pb} 77$ & 6.5 & 45 & 2 & $210 \mathrm{~Pb} \_16$ & 20.5 & 104 & 12 \\
$210 \mathrm{~Pb} 8$ & 7.5 & 53 & 3 & $210 \mathrm{~Pb} \_17$ & 22.5 & 146 & 37 \\
$210 \mathrm{~Pb} 9$ & 8.5 & 62 & 4 & & & &
\end{tabular}

Table S7. ${ }^{210} \mathrm{~Pb}$ dates used to create the South Twin Lake age model.

\begin{tabular}{|c|c|c|c|c|c|c|c|}
\hline Sample & $\begin{array}{l}\text { Depth } \\
\text { (cm) }\end{array}$ & Age (yr) & $\begin{array}{c}\text { Uncertainty } \\
\text { (yr) }\end{array}$ & Sample & $\begin{array}{l}\text { Depth } \\
\text { (cm) }\end{array}$ & Age (yr) & $\begin{array}{c}\text { Uncertainty } \\
(\mathrm{yr})\end{array}$ \\
\hline $210 \mathrm{~Pb} \_1$ & 0.5 & 3 & 0.3 & 210Pb_11 & 10.5 & 44 & 3 \\
\hline $210 \mathrm{~Pb} \_2$ & 1.5 & 7 & 0.4 & $210 \mathrm{~Pb} \_12$ & 12.5 & 55 & 3 \\
\hline $210 \mathrm{~Pb} \_3$ & 2.5 & 12 & 0.6 & $210 \mathrm{~Pb} \_13$ & 14.5 & 68 & 4 \\
\hline 210Pb_4 & 3.5 & 17 & 0.8 & $210 \mathrm{~Pb} \_14$ & 16.5 & 80 & 4 \\
\hline $210 \mathrm{~Pb} \_5$ & 4.5 & 22 & 1 & $210 \mathrm{~Pb} \_15$ & 18.5 & 90 & 4 \\
\hline 210Pb_6 & 5.5 & 26 & 1 & $210 \mathrm{~Pb} \_16$ & 20.5 & 95 & 5 \\
\hline $210 \mathrm{~Pb} \_7$ & 6.5 & 29 & 1 & $210 \mathrm{~Pb} \_17$ & 22.5 & 114 & 7 \\
\hline $210 \mathrm{~Pb} \_8$ & 7.5 & 33 & 2 & $210 \mathrm{~Pb} \_18$ & 24.5 & 135 & 9 \\
\hline $210 \mathrm{~Pb} \_9$ & 8.5 & 36 & 2 & $210 \mathrm{~Pb} \_19$ & 26.5 & 166 & 16 \\
\hline $210 \mathrm{~Pb} \_10$ & 9.5 & 40 & 2 & $210 \mathrm{~Pb} \_20$ & 28.5 & 186 & 38 \\
\hline
\end{tabular}


As noted in section 2.2, the Prentice-Sugita-Sutton model has certain assumptions (Sugita 1994, Gaillard et al. 2008), which we describe in full here:

1) that there is a comprehendible and spatially and temporally consistent relationship between pollen loading and distance-weighted plant abundance

2) the vegetation surface where the pollen is derived from is flat

3) the sampling basin is a circular opening in the canopy

4) pollen productivity (the amount of pollen produced per vegetation cover unit) is a constant for a given pollen taxon

5) pollen is dispersed as single grains

6) pollen dispersal is largely via wind above the canopy and gravity beneath the canopy, and pollen transport into a basin (canopy opening) can be modelled by considering the canopy component only

7) wind is uniform in every direction therefore pollen dispersal is evenly distributed around the source

8) most pollen deposition takes place via sedimentation due to gravity and deposition by interception is negligible

9) the deposition of pollen at a specified distance from a plant can be approximated using a diffusion model of the dispersal of small particles from a ground level source (Sutton 1953)

10) inter-taxon pollen grain differences (e.g., grain size, weight, and density) affect pollen dispersal and can be quantitatively estimated, and use of a single value to represent each taxon is sufficient to capture 


\section{PAR calculation}

After grains were counted, pollen concentrations and PAR were determined. Using the

Lycopodium marker grains, pollen concentrations $\left(C_{i}\right.$, grains $\left.\mathrm{cm}^{-3}\right)$ were calculated for each pollen type $i$ using the following equation:

$$
C_{i}=\frac{A_{i} \times L_{a}}{L_{c} \times V_{i}}
$$

Where $A_{i}$ is the number of pollen grains counted for the taxon $i, L_{a}$ is the number of added marker grains, $L_{c}$ is the number of counted marker grains in each slide, and $V_{i}$ is the volume of the pollen sample (e.g., $0.63 \mathrm{~cm}^{3}$ ) (Stockmarr 1971). Concentrations were used for PAR calculations by multiplying the concentration values by the sediment accumulate rate, which differed by lake site and was determined by the Plum age model in increments of $0.5 \mathrm{~cm}$. The equation used was:

$$
P A R_{i}=C_{i} \times S
$$

Where $\mathrm{PAR}_{\mathrm{i}}$ is the pollen accumulation rate for taxon $i, C_{i}$ is the pollen concentration (grains cm${ }^{3}$ ) for taxon $i$, and $S$ is the sedimentation rate $\left(\mathrm{cm} \mathrm{yr}^{-1}\right)$ (Davis and Deevey 1964). 
Table S8. Coefficients for the predicted aboveground live biomass $\left(\mathrm{Mg} \mathrm{ha}^{-1}\right)$ of trees as a function of basal area $\left(\mathrm{m}^{2} \mathrm{ha}^{-1}\right)$ using a linear log-log (natural) equation. Results for all species encountered in the forest inventory conducted for the seven lakes in the Klamath Mountains. The $\mathrm{p}$-value of the regression was $<0.0001$ in all cases except for white alder where $\mathrm{p}=0.034$. $\mathrm{B}_{0}$ is the intercept; $\mathrm{B}_{1}$ is the slope coefficient; SEE $=$ standard error of the estimate.

\begin{tabular}{lllcccc}
\hline Genus & Species & Common name & $\mathrm{B}_{\mathrm{o}}$ & $\mathrm{B}_{1}$ & $\mathrm{R}^{2}$ adj & $\begin{array}{c}\text { SEE } \\
\left(\mathrm{Mg} \mathrm{ha}^{-1}\right)\end{array}$ \\
\hline Abies & concolor & white fir & 1.65 & 1.07 & 0.95 & 0.40 \\
Abies & magnifica & California red fir & 1.47 & 1.19 & 0.92 & 0.46 \\
Acer & macrophyllum & bigleaf maple & 1.30 & 1.11 & 0.94 & 0.24 \\
Alnus & rhombifolia & white alder & 1.26 & 1.30 & 1.00 & 0.07 \\
Arbutus & menziesii & Pacific madrone & 1.55 & 1.12 & 0.94 & 0.29 \\
Calocedrus & decurrens & incense-cedar & 1.08 & 1.18 & 0.90 & 0.52 \\
Chamaecyparis & lawsoniana & Port-Orford-cedar & 1.16 & 1.19 & 0.97 & 0.37 \\
Chrysolepis & chrysophylla & golden chinquapin & 1.19 & 1.18 & 0.96 & 0.34 \\
Cornus & nuttallii & Pacific dogwood & 1.07 & 0.92 & 0.85 & 0.37 \\
Notholithocarpus & densiflorus & tanoak & 1.08 & 1.17 & 0.96 & 0.35 \\
Pinus & attenuata & knobcone pine & 1.18 & 1.06 & 0.96 & 0.21 \\
Pinus & jeffreyi & Jeffrey pine & 1.09 & 1.11 & 0.88 & 0.58 \\
Pinus & lambertiana & sugar pine & 1.67 & 1.22 & 0.85 & 0.59 \\
Pinus & ponderosa & ponderosa pine & 1.36 & 1.23 & 0.89 & 0.50 \\
Pseudotsuga & menziesii & Douglas-fir & 1.15 & 1.23 & 0.96 & 0.30 \\
Quercus & chrysolepis & canyon live oak & 1.47 & 1.12 & 0.92 & 0.43 \\
Quercus & kelloggii & California black oak & 1.62 & 1.11 & 0.96 & 0.27 \\
Taxus & brevifolia & Pacific yew & 0.83 & 0.82 & 0.94 & 0.21 \\
Umbellularia & californica & California-laurel & 0.95 & 1.30 & 0.95 & 0.38 \\
\hline
\end{tabular}


Table S9. Fall speed $(\mathrm{m} / \mathrm{sec})$ for major taxa used in the simulation runs of this study.

\begin{tabular}{cc}
\hline Taxa & $\begin{array}{c}\left.\text { Fall-speed ( } \boldsymbol{v}_{\boldsymbol{s}}\right) \\
\text { estimates }\left(\mathbf{m ~ s}^{-1}\right)\end{array}$ \\
\hline Abies & $0.120^{\mathrm{a}}$ \\
Alnus & $0.021^{\mathrm{b}}$ \\
Pinus & $0.031^{\mathrm{a}}$ \\
Pseudotsuga & $0.126^{\mathrm{a}}$ \\
Quercus & $0.035^{\mathrm{a}}$ \\
TCT & $0.016^{\mathrm{c}}$ \\
\hline & \\
\hline a Eisenhut $(1961){ }^{\mathrm{b}}$ Schober $(1975) ;$
\end{tabular}

c Calculated from empirical measurements using Stoke's Law with Falck's (1927) correction

Table S10. PAR values of main taxa from 2018 (a modeled age) at each lake site.

\begin{tabular}{cccccccc}
\hline Lake Site & Pinus & Pseudotsuga & Quercus & TCT & Notholithocarpus & Alnus & Abies \\
\hline Blue & 1760 & 5461 & 758 & 4490 & 1031 & 1183 & 789 \\
Red Mt. & 3672 & 5068 & 672 & 3051 & 2844 & 1034 & 569 \\
Onion & 10797 & 2014 & 1063 & 1622 & 559 & 951 & 4811 \\
North Twin & 1749 & 6808 & 1686 & 2311 & 2935 & 812 & 1999 \\
South Twin & 2384 & 7152 & 1463 & 2005 & 2059 & 1300 & 325 \\
Fish & 1479 & 4606 & 840 & 1782 & 3741 & 2858 & 34 \\
Ogaromtoc & 3376 & 4609 & 1558 & 844 & 454 & 1753 & 260 \\
\hline
\end{tabular}


Table S11. Results from the linear regressions predicting distance-weighted aboveground live biomass $\left(\mathrm{AGL}_{\mathrm{dw}}\right)$ as a function of pollen accumulation rate (PAR) for the pollen taxa present at the seven lake sites in the Klamath Mountains. The assemblage-level relevant source area of pollen (aRSAP) was defined as a circle with a radius of $625 \mathrm{~m}$ from centroid of the lake. Parameters provided the linear regression: $\mathrm{AGL}_{\mathrm{DW}}=\mathrm{B}_{0}+\mathrm{B}_{1} * \mathrm{PAR}$ where $\mathrm{AGL}_{\mathrm{dw}}$ is measured in $\mathrm{Mg} \mathrm{ha}^{-1}$; $\mathrm{PAR}$ in grains $\mathrm{cm}^{-2} \mathrm{yr}^{-1}$; $\mathrm{SEE}=$ standard error of the estimate; $\triangle \mathrm{AICc}=$ the difference in the Akaike Information Criterion for small samples between the top ranked model and the second ranked model.

\begin{tabular}{lcccccc}
\hline Pollen Taxa & $\Delta \mathrm{AICc}$ & $\mathrm{B}_{0}$ & $\mathrm{~B}_{1}$ & $\begin{array}{c}\mathrm{SEE} \\
\left(\mathrm{Mg} \mathrm{ha}^{-1}\right)\end{array}$ & $\mathrm{R}^{2}{ }_{\text {adj }}$ & $\mathrm{P}$ \\
\hline Pseudotsuga & 6.6 & 0 & 0.0180 & 19.1 & 0.96 & $<0.001$ \\
Pinus & 5.4 & 0 & 0.00740 & 8.42 & 0.94 & $<0.001$ \\
Notholithocarpus & 4.2 & 0 & 0.0211 & 16.5 & 0.89 & $<0.001$ \\
TCT & 4.0 & 0 & 0.00954 & 9.43 & 0.87 & $<0.001$ \\
Quercus $^{l}$ & & -- & -- & -- & -- & -- \\
Alnus & 3.0 & 3.8 & 0.00341 & 1.05 & 0.84 & 0.002 \\
Abies & 4.2 & 0 & 0.0138 & 13.8 & 0.80 & 0.0018
\end{tabular}

${ }^{1}$ There was no evidence of a significant linear relationship for Quercus. For predicting $\mathrm{AGL}_{\mathrm{dw}}$, a null model was used with the intercept $=1.54$ and the standard error $=1.46$.

Table S12. Results from the linear regressions predicting distance-weighted aboveground live biomass $\left(\mathrm{AGL}_{\mathrm{dw}}\right)$ as a function of pollen accumulation rate (PAR) for the pollen taxa present at the seven lake sites in the Klamath Mountains. The taxon-specific source area of pollen (tRSAP) was defined as a circle with a radius determined by the strength of correlation $\left(\mathrm{R}^{2}\right)$ between plant abundance and PAR. Parameters provided the linear regression: $\mathrm{AGL}_{\mathrm{dw}}=\mathrm{B}_{0}+\mathrm{B}_{1}$ * PAR where $\mathrm{AGL}_{\mathrm{DW}}$ is measured in $\mathrm{Mg} \mathrm{ha}^{-1}$; $\mathrm{PAR}$ in grains $\mathrm{cm}^{-2} \mathrm{yr}^{-1} ; \mathrm{SEE}=$ standard error of the estimate.

\begin{tabular}{lccccc}
\hline Pollen Taxa & $\mathrm{B}_{0}$ & $\mathrm{~B}_{1}$ & $\begin{array}{c}\text { SEE } \\
\left(\mathrm{Mg} \mathrm{ha}^{-1}\right)\end{array}$ & $\mathrm{R}^{2}{ }_{\text {adj }}$ & $\mathrm{P}$ \\
\hline Pseudotsuga & 0 & 0.0180 & 19.1 & 0.96 & $<0.001$ \\
Pinus & 0 & 0.00558 & 6.78 & 0.95 & $<0.001$ \\
Notholithocarpus & 0 & 0.0205 & 16.2 & 0.91 & $<0.001$ \\
TCT & 0 & 0.00849 & 8.97 & 0.87 & $<0.001$ \\
Quercus $^{l}$ & -- & -- & -- & -- & -- \\
Alnus & -3.8 & 0.00341 & 1.05 & 0.84 & 0.002 \\
Abies & 0 & 0.0138 & 13.8 & 0.83 & 0.0018
\end{tabular}

${ }^{1}$ There was no evidence of a significant linear relationship for Quercus. For predicting AGL $\mathrm{dw}_{\mathrm{d}}$ a null model was used with the intercept $=1.54$ and the standard error $=1.46$. 
Table S13. Results from the linear regressions predicting distance-weighted aboveground live biomass $\left(\mathrm{AGL}_{\mathrm{dw}}\right)$ as a function of pollen accumulation rate $(\mathrm{PAR})$ for the pollen taxa present at the seven lake sites in the Klamath Mountains. These equations all include an intercept and slope term even if they were not the best fit. The relevant source area of pollen (aRSAP) was defined as a circle with a radius of $625 \mathrm{~m}$ from centroid of the lake. Parameters provided the linear regression: $\mathrm{AGL}_{\mathrm{DW}}=\mathrm{B}_{0}+\mathrm{B}_{1} * \mathrm{PAR}$ where $\mathrm{AGL}_{\mathrm{dw}}$ is measured in $\mathrm{Mg}^{-1}$; $\mathrm{PAR}$ in grains $\mathrm{cm}^{-2} \mathrm{yr}^{-1} ; \mathrm{SEE}=$ standard error of the estimate.

\begin{tabular}{lccccc}
\hline Pollen Taxa & $\mathrm{B}_{0}$ & $\mathrm{~B}_{1}$ & $\begin{array}{c}\mathrm{SEE} \\
\left(\mathrm{Mg} \mathrm{ha}^{-1}\right)\end{array}$ & $\mathrm{R}^{2}$ adj & $\mathrm{P}$ \\
\hline Pseudotsuga & -14.7 & 0.0206 & 20.3 & 0.74 & 0.008 \\
Pinus & -5.5 & 0.00829 & 8.23 & 0.92 & $<0.001$ \\
Notholithocarpus & 16.8 & 0.0149 & 14.7 & 0.61 & 0.02 \\
TCT & -12.1 & 0.0138 & 8.33 & 0.78 & 0.005 \\
Quercus & -2.9 & 0.00386 & 3.84 & 0.0083 & 0.4 \\
Alnus & -3.8 & 0.00341 & 1.05 & 0.84 & 0.002 \\
Abies & -9.4 & 0.0168 & 12.35 & 0.84 & 0.002
\end{tabular}


Table S14. Dry bulk density $\left(\mathrm{g} \mathrm{cm}^{-3}\right)$ for Blue Lake.

\begin{tabular}{|c|c|c|}
\hline Lake & $\begin{array}{l}\text { Depth } \\
\text { (cm) }\end{array}$ & $\begin{array}{c}\text { Dry Bulk } \\
\text { Density }\left(\mathrm{g} \mathrm{cm}^{-3}\right)\end{array}$ \\
\hline Blue & $0-1$ & 0.102 \\
\hline Blue & $1-2$ & 0.093 \\
\hline Blue & $2-3$ & 0.085 \\
\hline Blue & $3-4$ & 0.095 \\
\hline Blue & $4-5$ & 0.088 \\
\hline Blue & $5-6$ & 0.087 \\
\hline Blue & $6-7$ & 0.089 \\
\hline Blue & $7-8$ & 0.085 \\
\hline Blue & $8-9$ & 0.084 \\
\hline Blue & $9-10$ & 0.078 \\
\hline Blue & $10-12$ & 0.087 \\
\hline Blue & $12-14$ & 0.096 \\
\hline Blue & $14-16$ & 0.102 \\
\hline Blue & 16-18 & 0.093 \\
\hline Blue & $18-20$ & 0.095 \\
\hline Blue & $20-21$ & 0.095 \\
\hline Blue & $22-23$ & 0.104 \\
\hline Blue & $24-25$ & 0.089 \\
\hline Blue & $26-27$ & 0.090 \\
\hline Blue & $28-29$ & 0.090 \\
\hline Blue & $30-31$ & 0.093 \\
\hline Blue & $40-42$ & 0.124 \\
\hline
\end{tabular}


Table S15. Dry bulk density $\left(\mathrm{g} \mathrm{cm}^{-3}\right)$ for Red Mountain Lake.

\begin{tabular}{|l|c|c|}
\hline Lake & Depth (cm) & $\begin{array}{c}\text { Dry Bulk Density } \\
\left(\mathbf{g ~ c m}^{-3}\right)\end{array}$ \\
\hline Red Mt. & $0-1$ & 0.080 \\
\hline Red Mt. & $1-2$ & 0.090 \\
\hline Red Mt. & $2-3$ & 0.074 \\
\hline Red Mt. & $3-4$ & 0.078 \\
\hline Red Mt. & $4-5$ & 0.068 \\
\hline Red Mt. & $5-6$ & 0.068 \\
\hline Red Mt. & $6-7$ & 0.071 \\
\hline Red Mt. & $7-8$ & 0.074 \\
\hline Red Mt. & $8-9$ & 0.079 \\
\hline Red Mt. & $9-10$ & 0.074 \\
\hline Red Mt. & $10-12$ & 0.081 \\
\hline Red Mt. & $12-14$ & 0.090 \\
\hline Red Mt. & $14-16$ & 0.112 \\
\hline Red Mt. & $16-18$ & 0.098 \\
\hline Red Mt. & $18-20$ & 0.110 \\
\hline Red Mt. & $20-21$ & 0.100 \\
\hline Red Mt. & $22-23$ & 0.121 \\
\hline Red Mt. & $24-25$ & 0.141 \\
\hline Red Mt. & $26-27$ & 0.146 \\
\hline Red Mt. & $28-29$ & 0.144 \\
\hline Red Mt. & $30-31$ & 0.150 \\
\hline Red Mt. & $35-37$ & 0.158 \\
\hline
\end{tabular}


Table S16. Dry bulk density $\left(\mathrm{g} \mathrm{cm}^{-3}\right)$ for Onion Lake.

\begin{tabular}{|c|c|c|}
\hline Lake & $\begin{array}{c}\text { Depth } \\
(\mathbf{c m})\end{array}$ & $\begin{array}{c}\text { Dry Bulk } \\
\text { Density }\left(\mathbf{g ~ c m} \mathbf{~}^{-3}\right)\end{array}$ \\
\hline Onion & $0-1$ & 0.084 \\
\hline Onion & $1-2$ & 0.093 \\
\hline Onion & $2-3$ & 0.082 \\
\hline Onion & $3-4$ & 0.074 \\
\hline Onion & $4-5$ & 0.073 \\
\hline Onion & $5-6$ & 0.065 \\
\hline Onion & $6-7$ & 0.049 \\
\hline Onion & $7-8$ & 0.047 \\
\hline Onion & $8-9$ & 0.061 \\
\hline Onion & $9-10$ & 0.082 \\
\hline Onion & $10-12$ & 0.128 \\
\hline Onion & $12-14$ & 0.140 \\
\hline Onion & $14-16$ & 0.157 \\
\hline Onion & $16-18$ & 0.195 \\
\hline Onion & $18-20$ & 0.224 \\
\hline Onion & $20-21$ & 0.235 \\
\hline Onion & $22-23$ & 0.227 \\
\hline Onion & $24-25$ & 0.228 \\
\hline Onion & $26-27$ & 0.246 \\
\hline Onion & $28-29$ & 0.189 \\
\hline Onion & $30-31$ & 0.223 \\
\hline
\end{tabular}


Table S17. Dry bulk density $\left(\mathrm{g} \mathrm{cm}^{-3}\right)$ for Fish Lake. 
Table S18. Dry bulk density $\left(\mathrm{g} \mathrm{cm}^{-3}\right)$ for South Twin Lake.

\begin{tabular}{|c|c|c|}
\hline Lake & $\begin{array}{c}\text { Depth } \\
\text { (cm) }\end{array}$ & $\begin{array}{c}\text { Dry Bulk Density } \\
\left(\mathbf{g ~ c m}^{-3}\right)\end{array}$ \\
\hline South Twin & $0-1$ & 0.076 \\
\hline South Twin & $1-2$ & 0.073 \\
\hline South Twin & $2-3$ & 0.067 \\
\hline South Twin & $3-4$ & 0.059 \\
\hline South Twin & $4-5$ & 0.054 \\
\hline South Twin & $5-6$ & 0.050 \\
\hline South Twin & $6-7$ & 0.045 \\
\hline South Twin & $7-8$ & 0.047 \\
\hline South Twin & $8-9$ & 0.047 \\
\hline South Twin & $9-10$ & 0.050 \\
\hline South Twin & $10-11$ & 0.051 \\
\hline South Twin & $12-13$ & 0.060 \\
\hline South Twin & $14-15$ & 0.064 \\
\hline South Twin & $16-17$ & 0.073 \\
\hline South Twin & $18-19$ & 0.067 \\
\hline South Twin & $20-21$ & 0.075 \\
\hline South Twin & $22-23$ & 0.083 \\
\hline South Twin & $24-25$ & 0.110 \\
\hline South Twin & $26-27$ & 0.130 \\
\hline South Twin & $28-29$ & 0.130 \\
\hline South Twin & $30-31$ & 0.154 \\
\hline
\end{tabular}


Table S19. Dry bulk density $\left(\mathrm{g} \mathrm{cm}^{-3}\right)$ for Ogaromtoc Lake.

\begin{tabular}{|c|c|c|}
\hline Lake & Depth (cm) & $\begin{array}{c}\text { Dry Bulk } \\
\text { Density (g cm} \\
\mathbf{3}\end{array}$ \\
\hline Ogaromtoc & $0-1$ & 0.086 \\
\hline Ogaromtoc & $1-2$ & 0.083 \\
\hline Ogaromtoc & $2-3$ & 0.064 \\
\hline Ogaromtoc & $3-4$ & 0.064 \\
\hline Ogaromtoc & $4-5$ & 0.065 \\
\hline Ogaromtoc & $5-6$ & 0.068 \\
\hline Ogaromtoc & $6-7$ & 0.072 \\
\hline Ogaromtoc & $7-8$ & 0.074 \\
\hline Ogaromtoc & $8-9$ & 0.071 \\
\hline Ogaromtoc & $9-10$ & 0.066 \\
\hline Ogaromtoc & $10-11$ & 0.068 \\
\hline Ogaromtoc & $12-13$ & 0.081 \\
\hline Ogaromtoc & $14-15$ & 0.366 \\
\hline Ogaromtoc & $16-17$ & 0.116 \\
\hline Ogaromtoc & $18-19$ & 0.072 \\
\hline Ogaromtoc & $20-21$ & 0.096 \\
\hline Ogaromtoc & $22-23$ & 0.268 \\
\hline Ogaromtoc & $24-25$ & 0.147 \\
\hline Ogaromtoc & $26-27$ & 0.066 \\
\hline Ogaromtoc & $28-29$ & 0.061 \\
\hline Ogaromtoc & $30-31$ & 0.064 \\
\hline
\end{tabular}


Table S20. Dry bulk density $\left(\mathrm{g} \mathrm{cm}^{-3}\right)$ for North Twin Lake.

\begin{tabular}{|c|c|c|}
\hline Lake & Depth (cm) & $\begin{array}{c}\text { Dry Bulk } \\
\text { Density (g/cm³) }\end{array}$ \\
\hline North Twin & $0-1$ & 0.099 \\
\hline North Twin & $1-2$ & 0.097 \\
\hline North Twin & $2-3$ & 0.101 \\
\hline North Twin & $3-4$ & 0.107 \\
\hline North Twin & $4-5$ & 0.108 \\
\hline North Twin & $5-6$ & 0.106 \\
\hline North Twin & $6-7$ & 0.092 \\
\hline North Twin & $7-8$ & 0.076 \\
\hline North Twin & $8-9$ & 0.076 \\
\hline North Twin & $9-10$ & 0.088 \\
\hline North Twin & $10-12$ & 0.132 \\
\hline North Twin & $12-14$ & 0.143 \\
\hline North Twin & $14-16$ & 0.145 \\
\hline North Twin & $16-18$ & 0.145 \\
\hline North Twin & $18-20$ & 0.141 \\
\hline North Twin & $20-21$ & 0.122 \\
\hline North Twin & $22-23$ & 0.133 \\
\hline North Twin & $24-25$ & 0.127 \\
\hline North Twin & $26-27$ & 0.137 \\
\hline North Twin & $28-29$ & 0.135 \\
\hline North Twin & $30-31$ & 0.137 \\
\hline & & \\
\hline
\end{tabular}




\section{References}

Appleby P and Oldfield F (1978) The calculation of lead-210 dates assuming a constant rate of supply of unsupported $210 \mathrm{~Pb}$ to the sediment. Catena $5: 1-8$.

Baskaran M, Miller CJ, Kumar A et al. (2015) Sediment accumulation rates and sediment dynamics using five different methods in a well-constrained impoundment: Case study from Union Lake, Michigan. Journal of Great Lakes Research 41:607-617.

Davis MB and Deevey ES (1964) Pollen accumulation rates: estimates from Late-Glacial sediment Rogers Lake. Science 145:1293-1295.

Eisenhut G (1961) Untersuchungen über die Morphologie und Ökologie der Pol- lenkörner heimischer und fremdländischer Waldbäume. Paul Parey, Hamburg.

Falck R (1927) Über die Größen, Fallgeschwindigkeit und Schwebewarte dcr Pilzsporen und ihre Gruppierung mit Bezug auf die zu ihre Verbreitung nötigen temperatuströmungs-Geschindigkeit. Berichte der Deutschen Botanischen Gesesellschaft 45:262-281.

Gaillard MJ, Sugita S, Bunting MJ et al. (2008) The use of modelling and simulation approach in reconstructing past landscapes from fossil pollen data: a review and results from the POLLANDCAL network. Vegetation History and Archaeobotany 17:419-443.

Jweda J and Baskaran M (2011) Interconnected riverine-lacustrine systems as sedimentary repositories: Case study in southeast Michigan using 210-Pb and 137-Cs sediment accumulation and mixing models. Journal of Great Lakes Research 37:432-446.

Schober, R., 1975. Ertragstafeln wichtiger Baumarten bei verschiedener Durchfor- stung. Sauerländer, Frankfurt a. M.

Stockmarr J (1971) Tablets with spores used in pollen analysis. Pollen and Spores 13:615-621.

Sugita S (1994) Pollen representation of vegetation in Quaternary sediments: Theory and method in patchy vegetation. Journal of Ecology 82:881-897. 